\title{
8 \\ EFEITOS CONGLOMERADOS NA JURISPRUDÊNCIA DO CADE
}

\section{Conglomerate effects in Cade's jurisprudence}

\author{
Maria Cristina de Souza Leão Attayde ${ }^{1}$
}

\section{RESUMO}

Recentemente tem-se notado o ressurgimento de preocupações concorrenciais relativas a efeitos conglomerados em concentrações econômicas em virtude principalmente da importância crescente da tecnologia digital. Nesse contexto, o artigo analisa a aplicação dos chamados efeitos conglomerados nas decisões e análises de atos de concentração feitas pelo Cade, a partir da vigência da Lei no 12.529/2011. Primeiramente foram apresentadas algumas questões conceituais relativas a efeitos conglomerados, o contexto histórico no qual surgiram importantes discussões antitruste, assim como algumas das novas abordagens da doutrina, especificamente em relação economia digital. No que tange à jurisprudência do Cade, foram abordadas as teorias do dano aplicadas nas análises de efeitos conglomerados. Notam-se avanços nesse tipo de análise nos seguintes aspectos: (i) ampliação da análise, para além do chamado efeito portfólio, com a incorporação de outras teorias do dano; e (ii) a utilização crescente de análises econômicas por meio de estudos quantitativos e qualitativos.

Palavras-chave: Efeitos conglomerados; atos de concentração; Cade, jurisprudência; Lei no 12.529/2011.

\begin{abstract}
Recently there has been a revival of interest in conglomerate effects, specially in response to the growing importance of digital technology. In this context, the article aims to analyze the conglomerate effects in Brazil merger control since the Law no 12.529/2011. At first, it is presented conceptual issues regarding conglomerate mergers, the historical context of discussions concerning conglomerate effects and new approaches of antitrust doctrine, specially with regard to digital economy. Subsequentlly, it was analysed the Cade's jurisprudence, specifically theories of harm applied in conglomerate effects. In this respect, it is noted that there have been advances: (i) Cade's jurisprudence has used other theories of harm, beyond the portfolio power; (ii) growing use of economic reviews, i.e., empirical studies and qualitative assessment.
\end{abstract}

Keywords: Conglomerate effects, merger control, CADE, jurisprudence, Law № 12.529/2011.

1 Bacharel em Ciências Econômicas pela Universidade Federal do Rio de Janeiro e Especialista em Políticas Públicas e Gestão Governamental. Atuou na Secretaria de Acompanhamento Econômico - SEAE/MF e Secretaria de Direito Econômico/ MJ. Autora de artigos e monografia nas áreas de concorrência e regulação, entre eles, VII Prêmio SEAE 2012, 2o lugar, na área de Advocacia da Concorrência. Atualmente atua no Conselho Administrativo de Defesa Econômica - Cade, especificamente no Departamento de Estudos Econômicos. E-mail: cristinasl100@gmail.com 
Sumário: 1. Introdução; 2. Efeitos conglomerados e a doutrina recente; 3. Teorias do dano; 4. Efeitos conglomerados na era digital; 5. Conclusão; 6. Referências; 7. Anexo.

\section{INTRODUÇÃO}

O presente artigo pretende avaliar a aplicação dos chamados efeitos conglomerados nas análises dos atos de concentração feitas pelo Conselho Administrativo de Defesa Econômica - Cade a partir do advento da Lei no 12.529/2011². Em geral, efeitos conglomerados têm sido considerados menos preocupantes sob o ponto de vista de uma análise antitruste tradicional, sendo que, em muitos casos, esses efeitos são analisados sob o rito sumário ${ }^{3}$. No entanto, tem havido uma crescente preocupação por parte de autoridades antitruste, inclusive o Cade, tendo em vista o ressurgimento de grandes conglomerados potencializado pela tecnologia digital.

Atos de concentração que originam concentração conglomeral, por definição, não alteram a estrutura do mercado, pois não implicam concentrações horizontais, nem integrações verticais. Logo, os efeitos conglomerados podem ser considerados indiretos, pois as partes não atuam nos mesmos mercados relevantes (concentração horizontal), e nem em mercados verticalmente relacionados nos quais agentes econômicos possuem uma relação atual ou potencial de fornecedor-cliente, ou seja, ofertam produtos ou serviços pertencentes a etapas diferentes da mesma cadeia produtiva. Isso significa que os produtos e/ou serviços que as partes ofertam no mercado são, de maneira geral, complementares ou não diretamente relacionados ${ }^{4}$.

Nesse sentido podem-se classificar as operações conglomeradas em três tipos: (i) aquelas voltadas a diversificar linhas de produtos, i.e., fabricam produtos complementares por natureza, pois possuem semelhanças em processos de produção, publicidade e/ou distribuição (operações de extensão de produto); (ii) aquelas voltadas à diversificação geográfica da atuação das partes, ou seja, ofertam o mesmo produto, mas atuam em mercados relevantes geográficos distintos por meio de multiunidades (operações de extensão de mercado); e (iii) outras, dentre as quais aquelas que visam à entrada em um novo mercado, não antes explorado pela parte adquirente (operações conglomera-

2 A Lei no 12.529/2011, que instituiu uma nova estrutura ao Sistema Brasileiro de Defesa da Concorrência trata, entre outras disposições, da alteração do sistema de análise de atos de concentração, que passa de posterior para prévio, ou seja, antes da consumação da fusão ou aquisição. Nesse contexto, o Cade passou a ter a função preventiva de controle de concentração de poder econômico de mercado.

3 Exemplos de atos de concentração sumários recentes que analisaram poder de portfólio: 08700.002780/201965 (Requerentes: QIAGEN GMBH e General Eletric Company); 08700.002403/2019-26 (Requerentes: Cameron International Corporation (Grupo Schlumberger) e Subsea 7 Holdings (US) Inc. (Grupo Subsea 7).

4 Visto que não há uma definição padrão para efeitos conglomerados, Neven (2005) argumenta que efeitos conglomerados estão relacionados a produtos que podem ser complementares, substitutos fracos ou independentes pelo lado da demanda. Substitutos fracos referem-se a produtos que estão em mercados adjacentes, o que geram os chamados efeitos portfólios. Nesse sentido, efeitos conglomerados podem ser considerados como efeitos indiretos, pois não ocorrem no mesmo mercado relevante; no entanto tais efeitos só acontecem quando há consumidores em comum. Ver: NEVEN, D. (2005) The analysis of conglomerate effects in EU merger control. 
das puras) $)^{5}$

Pode-se afirmar que operações de extensão de produto estão intrinsecamente relacionadas à possibilidade de aumento de poder de portfólio - a modalidade de efeitos conglomerados mais analisada pelo Cade.

Nesse sentido, efeitos conglomerados são possiveis efeitos anticompetitivos ou não decorrentes de fusões/aquisições conglomerais. Estes efeitos podem ser, por exemplo, redução de custos de transação, fechamento de mercado, práticas exclusionárias ou discriminatórias, preços predatórios por meio de subsídios cruzados, entre outros. Há pelo menos quatro teorias do dano relativas a potenciais impactos anticompetitivos causados por fusões/aquisições conglomeradas que se destacam na doutrina (vide Seção 3), sendo que o aumento do poder de portfólio é o mais destacado.

Vale ressaltar que efeito portfólio não é sinônimo estrito de efeito conglomerado, mas sim uma das modalidades de efeitos decorrentes do poder conglomerado. Poder de portfólio está relacionado à oferta de uma ampla gama de produtos complementares de tal forma que a detenção de tais produtos pode provocar dois tipos de efeitos: (i) os custos de transação dos clientes podem ser diminuídos quando ele passa a lidar apenas com uma empresa que possui diversos tipos de produtos e marcas, ao invés de vários pequenos fornecedores (o relacionamento com muitos fornecedores importa em custos de transação decorrentes de negociações de preços e condições com cada produto, realização de contratos, relacionamento com diferentes equipes de vendas, entre outros); (ii) o aumento gradativo da dificuldade dos concorrentes rivalizarem com a empresa que detém tal poder, ao terem os seus acessos aos pontos de venda dificultados em virtude de condutas como tying e bundling 6 .

A partir da definição de operações conglomerais e efeitos conglomerados constante nesta introdução, a Seção 2 acrescenta alguns aspectos conceituais, o contexto histórico no qual surgiram importantes discussões antitruste e apresenta algumas das novas abordagens da doutrina. A Seção 3 trata de teoria do dano, i.e., tipologia, teorias do dano apresentadas pelos Conselheiros, e as análises econômicas decorrentes. A Seção 4 trata de desafios colocados ao Cade diante da economia digital e, por fim, na Seção 5 apresentam-se as conclusões.

\section{EFEITOS CONGLOMERADOS E A DOUTRINA RECENTE}

Conglomerados são grandes estruturas empresariais formadas por inúmeras empresas independentes que atuam em mercados não relacionados ou pouco relacionados, seja, na produção, distribuição ou comercialização de bens e/ou serviços.

Conforme mencionado anteriormente, fusões conglomeradas envolvem empresas que não

5 Fonte: GOLDBERG, L. The Effect of Conglomerate Mergers on Competition. The Journal of Law \& Economics, v. 16/1, p. 137-158, 1973; e HOVENKAMP, H. Federal Antitrust Policy. 4. ed. Hornbook series, p. 336 a 337, 2011

6 Simplificadamente, pode-se afirmar que tying (venda casada) ocorre quando a venda de um dos produtos está condicionada pela venda do outro - também chamado de pure bundling. Bundling, ou mixed bundling ocorre quando a empresa vende dois ou mais produtos tanto em forma de pacotes, como em separado. Esta é a forma mais comum, por exemplo, no mercado de telecomunicações. Fonte: OECD. Triple and Quadruple Play Bundles of Communication Services. OECD Science, Technology and Industry Policy Papers, n. 23, 2015 
atuam no mesmo mercado de produto e nem em diferentes estágios sucessivos da mesma cadeia produtiva. Logo, sob a ótica do produto, fusões conglomeradas podem envolver os seguintes tipos de bens:

i. Complementares: bens econômicos que devem ser combinados para satisfazer de terminada necessidade; quando utilizados em conjunto, aumenta-se a sua utilidade. Exemplo: hardware e software de computador.

ii. Substitutos fracos: produtos que estão em mercados adjacentes, o que geram os chamados efeitos portfólios. Apesar de não estarem no mesmo mercado relevante, há consumidores em comum. (NEVEN, 2005).

iii. Não relacionados: produtos que não são nem substitutos, nem complementares. No entanto, esses bens podem envolver insumos similares ou serem ofertados como parte de um conjunto de produtos pertencentes a mesma marca. Exemplo: motor para avião e motor para barco. (OCDE, 2020).

É importante ressaltar que há a possibilidade de fusões conglomeradas que envolvem bens similares. Isso ocorre quando a operação implica extensão de mercado, ou seja, uma empresa local é adquirida por uma empresa com várias unidades territoriais que oferta o mesmo produto/serviço em diferentes mercados relevantes geográficos.

Ademais, atos de concentração que implicam efeitos conglomerados trazem, em geral, outros tipos de concentrações como sobreposições horizontais e/ou integrações verticais. Em contraposição, há fusões conglomeradas puras, que implicam somente efeitos conglomerados.

Historicamente, nos anos 60 e 70, uma onda de fusões conglomeradas suscitou um amplo debate, tanto em termos de política antitruste, quanto nos círculos acadêmicos, com relação às motivações das empresas em expandir para mercados não relacionados (ou pouco relacionados), assim como em relação à lucratividade dessa estratégia. Além disso, tentou-se avaliar se essas fusões suscitavam preocupações por parte das autoridades antitruste, visto que, a priori, essas operações não pareciam motivadas por um aumento de poder de mercado. (BOURREAU e STREEL, 2019, p. 5)

Vale destacar que em 1967, o US Federal Trade Commission (FTC) proibiu, pela primeira vez, uma fusão cujo foco eram efeitos conglomerados. Trata-se do caso Procter \& Gamble-Clorox, no qual, a posição do FTC em proibir a fusão prevaleceu na Suprema Corte norte-americana em 11/04/19677.

Nesse contexto, surgiram inúmeras teorias econômicas nas décadas de 60 e 70 que buscavam explicar o fenômeno das fusões conglomeradas, as vantagens do processo de diversificação em

7 Resumidamente, a proibição da fusão baseou-se nas seguintes alegações: (i) Procter \& Gamble era uma das poucas entrantes potenciais no mercado de alvejantes líquidos e assim a aquisição da Clorox iria afetar a concorrência presente e futura nesse mercado; (ii) visto que à época Procter \& Gamble era um grande anunciante, o segmento Clorox seria mantido com custos publicitários menores em relação aos competidores e, consequentemente, estaria apta a aumentar sua participação no mercado. Assim como nos serviços de publicidade, alegou-se que fusões conglomeradas concedem vantagens indevidas à empresa adquirente devido a economias em outros fatores como serviços jurídicos, serviços de informática, P\&D, lobbying e acesso ao mercado de capitais. Fonte: Goldberg, L. (1973), "The Effect of Conglomerate Mergers on Competition", The Journal of Law \& Economics, Vol. 16/1, pp. 137-158. 
mercados pouco relacionados e possíveis danos concorrenciais advindos dessas operações ${ }^{8}$.

À essa época, a jurisprudência norte-americana, ao decidir pela reprovação ou com restrições operações com efeitos conglomerados, baseou-se em diferentes teorias do dano, que podem ser condensadas em 4 grupos: (i) teoria da atuação transversal (Reciprocity Dealings Theory), (ii) fortalecimento do poder econômico (Entrenchment Doctrine), (iii) eliminação da concorrência potencial (Substantial Lessening of Competition) e (iv) aumento da concentração agregada (Increase of Aggregate Concentration). (BUNDESKARTELLAMT, 2006, p. 3 a 5)

Nota-se que uma das teorias do dano mais recorrentes na jurisprudência do Cade é a chamada teoria da atuação transversal (Reciprocity Dealings Theory) na qual, em linhas gerais, a empresa emprega seu poder sobre determinado mercado para induzir sua atuação em outros mercados, em especial, com relação a bens/serviços complementares ou relacionados (maiores detalhes, vide Seção 3).

Recentemente, novas abordagens de teorias do dano relativas a efeitos conglomerados têm-se destacado. Conglomerados industriais das décadas de 60 e 70 têm sido substituídos por empresas digitais gigantes, com crescente poder de mercado e atuação transversal em vários setores da economia por meio de plataformas que atuam como marketplaces, ou seja, conectam compradores e vendedores.

As chamadas big techs (e.g., Apple, Google, Facebook e Amazon) têm se expandido em vários setores da economia, inclusive em mercados não relacionados. A título de exemplo, a Amazon, que no início, dedicava-se apenas ao comércio eletrônico de livros, expandiu-se para vários tipos de produtos/serviços, na sua maioria, por meio de aquisições de empresas. Os segmentos nos quais a Amazon atua inclui comércio eletrônico de livros, edição de livros, serviços de pagamento, serviços de computação em nuvem, serviços de financiamento, mercado de distribuição de produtos farmacêuticos, supermercado online, fabricação de hardware, serviços de seguro, serviços de streaming de música, mercado de distribuição e produção de filmes e séries de TV, além de atuar como rede de entrega e logística e como plataforma de publicidade, entre outros. Logo, pode-se considerar, nos dizeres de Khan (2017), que a Amazon representa um titã do século XXI, pois além de ser o centro do comércio eletrônico, também atua como infraestrutura essencial que abriga outros negócios?

8 Bourreau e Streel (2019, p. 4 a 7) apresentam resumidamente as principais teorias econômicas, no âmbito de Organização Industrial (OI), que explicam a onda de fusões conglomeradas que ocorreram na década de 60 e 70: agency theory, market power theory, resource theory e internal capital market theory. Além disso, os autores trazem uma breve discussão sobre em que medida essas teorias explicam o crescimento de conglomerados digitais.

9 KHAN, Lina M. Amazon's Antitrust Paradox, The Yale Law Journal, volume 126, número 3, 2017. A autora, ao discorrer sobre a forma de atuação da Amazon, faz uma análise crítica das limitações do atual arcabouço antitruste, em especial, a teoria do bem-estar do consumidor, em captar novas formas de abuso de poder de mercado, especificamente no contexto de plataformas online. A doutrina corrente, ao avaliar a concorrência, principalmente por meio de variáveis como preço e quantidade, além de negligenciar, em muitas situações, os riscos concorrenciais de estratégias, como preço predatório, assim como estratégias de integração entre diferentes linhas de negócios, revela deficiências em captar a arquitetura de poder de mercado na economia moderna. 
Bourreau e Streel (2019, p. 7 a 10) argumenta que, pelo lado da oferta, economias de escopo ${ }^{10}$ exercem um papel fundamental em mercados digitais, não apenas no processo de produção, mas principalmente no desenvolvimento de novos produtos por meio do compartilhamento de insumos (inputs) tais como dados, hardware, software e algoritmos. Logo, economias de escopo tornam-se fator chave de explicação da estratégia de diversificação adotada por empresas digitais.

Os autores citam, a título de exemplo, a Apple que tem desenvolvido internamente uma gama de processadores que são utilizados e reutilizados no desenvolvimento de produtos como iPhone e iPads. O compartilhamento desses processadores reduz o custo de desenvolvimento de cada novo device. Ademais, a modularidade do modelo de produtos digitais permite que determinado produto (e.g., serviço de localização - map service) sirva de insumo para outro produto (e.g., sistemas de navegação).

Visto que empresas digitais têm capacidade de coletar uma imensa quantidade de dados sobre consumidores, há a possibilidade de utilização desses dados como insumos compartilháveis pois são bens não rivais - o que leva também a economias de escopo no desenvolvimento de novos produtos, assim como a possibilidade de melhor monetizar a atenção do consumidor - em diferentes dispositivos (e.g., de notebook para celular, para tablet) ou aplicativos (e.g., Facebook) - por meio da publicidade online direcionada. (BOURREAU e STREEL, 2019, p. 9)

Acrescente-se que controle sobre dados é amplificado e pode implicar barreiras à entrada quando se analisa as formas de atuação de plataformas online. Khan (2017), ao estudar as estratégias de mercado da Amazon, argumenta que uma das fontes de poder de plataformas online advém de um duplo papel: ao mesmo tempo que atua como varejista, também atua como marketplace, o que permite a ela coletar vários tipos de dados como dados de consumo, de vendas de potenciais rivais, de pesquisa por produtos, entre outros. Com isso, o controle sobre dados permite às plataformas online amoldar melhor os serviços oferecidos, avaliar a demanda, alavancar outras linhas de negócios e até eliminar concorrentes.

Por fim, pelo lado da demanda, há as sinergias de consumo que podem ser geradas por ecossistemas de produto, ou seja, quando há interações (vínculos) entre diferentes produtos e/ou serviços, possivelmente não relacionados, ofertados pela mesma empresa, o que permite ao consumidor o compartilhamento de funcionalidades entre produtos. Por exemplo, Apple Watch pode apenas ser usado conjuntamente com um iPhone da Apple e não com um smartphone de outro fabricante. (BOURREAU e STREEL, 2019, p. 10)

Logo, essas duas características, ou seja, sinergias tanto pelo lado da oferta, quanto pelo lado da demanda, favorecem o desenvolvimento de amplos portfólios de produtos por empresas digitais.

Nesse contexto, discussões sobre possiveis distorções concorrenciais advindas de fusões conglomeradas têm abordado questões como efeitos coordenados por meio de práticas colusivas e condutas unilaterais relativas a fechamento de mercado por meio de práticas como tying e bundling.

10 Economias de escopo ocorrem quando se torna menos dispendioso produzir 2 ou mais produtos ou serviços dentro de uma única firma do que por firmas separadas em virtude da existência de insumos compartilháveis no processo de produção. Caso esses produtos/serviços pertençam a mercados não relacionados ou pouco relacionados, a expansão permitida por economias de escopo gera firmas conglomeradas. 
Com relação a efeitos coordenados ${ }^{11}$, Cheng (2017, p. 62) argumenta que interações repetidas entre conglomerados atuantes em múltiplos mercados tornam mais prováveis condutas paralelas. Caso essas condutas excluam novos concorrentes, tem-se a chamada exclusão paralela, o que torna um sério problema concorrencial.

A exclusão paralela é um novo conceito no direito da concorrência e está relacionado a condutas, por parte de conglomerados, de autoentrincheiramento, que abrange múltiplas firmas e prejudicam a concorrência ao limitar perspectivas concorrenciais de rivais ou de potenciais rivais. Esquemas de exclusão paralela, em geral, não são resultado de um plano deliberado, mas sim decorrentes da manutenção de práticas costumeiras ${ }^{12}$.

Tendo em vista que o padrão exclusionário pode ser replicado em diferentes mercados, conglomerados exacerbam esse efeito tornando condutas de exclusão mais prováveis a aumentar e a permanecerem estáveis. (CHENG, 2017, p. 64)

Assim como condutas exclusionárias ganham novas abordagens quando se analisam efeitos conglomerados, tying e bundling têm sido alvo de maior preocupação por parte da doutrina.

Neven (2005, p. 38), ao analisar a jurisprudência da Comissão Europeia relativa a efeitos anticompetitivos em fusões conglomeradas, destaca dois efeitos anticoncorrenciais em um contexto de práticas tying e bundling: Caso não haja competição efetiva em determinado mercado e condições necessárias para bundling puro sejam encontradas, podem ocorrer dois tipos de conduta: (i) potencial aumento de acordos colusivos (quando, na ausência de uma complementaridade estrita, o mercado de bens condicionantes (tying goods) ${ }^{13}$ for segmentado e a concorrência no mercado de bens condicionados (tied goods) for intensa; e (ii) possibilidade de práticas exclusionárias [quando os bens são complementares estritos, as empresas fusionadas tem um forte incentivo a excluir, intensificado quando a exclusão tem efeitos dinâmicos a longo prazo (efeitos de rede)].

11 Coordenação explícita: cartéis - há a necessidade de trocas de informações entre os membros do grupo. São as trocas de informações que permitem o estabelecimento dos termos do acordo, o monitoramento da conformação do comportamento dos integrantes, as condições para a imposição de sanções, etc. Coordenação tácita: não há a necessidade de trocas de informação. O elemento central que torna possivel a coordenação sem troca de comunicação é a interação repetida dos concorrentes no mercado. Não é uma conduta ilícita per se, mas é uma conduta anticompetitiva, que deve ser evitada em âmbito de controle prévio de estruturas. Consultar em: http://www.cade.gov.br/acesso-a-informacao/ publicacoes-institucionais/guias_do_Cade/guia-para-analise-de-atos-de-concentracao-horizontal.pdf e http://www.cade. gov.br/servicos/perguntas-frequentes/perguntas-sobre-infracoes-a-ordem-economica Acesso: 10/11/2020.

12 Hemphill e Wu (2012) analisam seis mecanismos de exclusão paralela. Resumidamente são: (i) exclusão simples quando as táticas de exclusão não envolvem acordos com outras partes, e os custos de exclusão são relativamente baixos; (ii) recrutamento de agentes - há a necessidade de recorrer a terceiros para efetuar exclusões. É um mecanismo que pode ser oneroso a quem exclui, pois os agentes precisam ser compensados ou ameaçados pela perda de lucro ou pela renúncia de oportunidades; (iii) compra excessiva de um insumo essencial privando o acesso aos potenciais entrantes; (iv) tying - o mercado no qual a exclusão tem como alvo é em geral o mercado de bens condicionados (tied product), e não no mercado de bens condicionantes (tying product); (v) manutenção paralela dos preços de revenda - a exclusão é obtida por meio do fornecimento a múltiplos varejistas no mercado downstream uma margem de lucro atrativa e, consequentemente, um forte incentivo econômico a atuar no interesse dos produtores do mercado upstream, o que inclui a exclusão de potenciais entrantes no mercado upstream; e (vi) Cláusula da Nação mais Favorecida - a exclusão é obtida quando dificulta-se a um novo comprador entrante fontes mais baratas de fornecimento. Isso porque a extensão de um preço baixo a um comprador implicaria descontos a todos os compradores downstream, o que um vendedor upstream não estaria disposto a conceder

Tying good é o bem que para ser adquirido, condiciona a aquisição de outro bem (tied good). 
O autor acrescenta que a Comissão Europeia reconhece potenciais danos concorrenciais advindos de fusões conglomeradas (extensão de produto e extensão de mercado), mas ainda não há uma política clara, em especial com relação à aplicação de remédios antitruste. Remédios comportamentais que proíbem tying/bundling, ao contrário de controle de preços, tem maior potencial de monitoramento, pois os consumidores podem facilmente perceber e denunciar à Comissão. Isso proporciona um incentivo às empresas em cumprir tais medidas. (NEVEN, 2005, p. 39 e 40)

Há autores, por sua vez, que argumentam que conglomerados digitais amplificam efeitos concorrenciais da prática de bundling e consideram que esta prática pode ser um instrumento anticompetitivo.

Pelo lado positivo, bundling permite às empresas conglomeradas e aos consumidores beneficiarem-se de economias de escopo pelo lado da oferta e pelo lado da demanda. No entanto, a prática de bundling por empresas conglomeradas aumenta os riscos de (i) elevar barreiras à entrada a empresas inovadoras entrantes que visam atuar em nichos de mercado; (ii) aumentar a diferenciação, diminuindo a concorrência, (iii) servir de instrumento a grandes plataformas que se baseiam, pelo lado da oferta, de economias de escopo, e pelo lado da demanda, em efeitos de rede, para eliminar concorrentes que atuam em mercados adjacentes; entre outros. (BOURREAU, 2012, p. 33, 34).

Tirole (2019) $)^{14}$, na mesma linha, argumenta que práticas de bundling pelas gigantes de tecnologia são concorrencialmente preocupantes. Uma empresa startup pode ser uma concorrente eficiente em um nicho de mercado. Porém, é muito dificil entrar em todos os segmentos ao mesmo tempo. Assim a prática de bundling pode impedir a entrantes eficientes o acesso a segmentos de mercado e de desafiar tecnologicamente empresas incumbentes. 0 autor exemplifica essa situação:

New entrants into online markets often begin with a niche product; if it proves successful, they expand to offer a much wider range of products and services. Google began with only its search engine before it became the company we know today; Amazon started by selling books. So what matters is whether new entrants can access the market in the first place. If a newcomer has a single original product that is better than what the incumbent offers, the incumbent might want to block it from gaining even a partial foothold in the market. The incumbent will do so not to improve its short-term profits, but to prevent the newcomer from later competing in areas where the incumbent occupies a monopoly position, or to stop the newcomer from allying with the dominant firm's competitors (TIROLE, 2019)

Da mesma forma Tirole (2019) considera que a prática de venda casada (tying) pode impedir o acesso a entrantes em uma gama de setores do mercado digital.

This is why "tie-in sales" are a particularly pernicious anticompetitive practice. By requiring purchasers of one of its products to also buy a suite of other products, a monopoly firm can deny market access to new entrants across a

14 Consultar em: https://www.livemint.com/Technology/XsgWUgy9tR4uaoME7xtITI/Regulating-the-disrupters-JeanTirole.html Acesso: 11/09/2020. 
range of areas. And yet it is impossible to formulate a one-size-fits-all policy for this problem. Whether competition authorities should forbid a dominant company from using tie-in sales or similar gambits (loyalty rebates, for example) will depend on their motive and rationale. (TIROLE, 2019)

Por conseguinte, pode-se afirmar que debates recentes sobre fusões conglomeradas estão intrinsecamente relacionados com preocupações concorrenciais advindas da amplificação de seus efeitos, em decorrência de características intrínsecas da economia digital.

A seguir, o artigo irá dedicar-se teorias do dano no que se refere à tipologia e jurisprudência do Cade, o que inclui resumidamente as análises econômicas de operações conglomerais.

\section{TEORIAS DO DANO}

\subsection{Tipologia}

Há pelo menos quatro teorias do dano relativas a potenciais danos causados por fusões conglomeradas que se destacam na doutrina. Essas teorias remontam às décadas de 60 e 70, no contexto da jurisprudência norte-americana, e algumas delas têm sido aplicadas de forma recorrente nos dias de hoje. Resumidamente, são as seguintes ${ }^{15}$ :

(a) Teoria da atuação transversal (Reciprocity dealings)

A atuação transversal ocorre quando uma empresa emprega seu poder sobre um mercado específico para alavancar sua atuação em outros mercados, em especial quando se tratam de bens complementares ou relacionados. Tal teoria baseia-se no chamado poder de portfólio, ou seja, na possibilidade da adquirente (uma das requerentes) do ato de concentração induzir fornecedores ou clientes a contratarem a outra requerente nos mercados nos quais esta atua, não devido às características intrínsecas do produto e/ou serviço (e.g., preço, qualidade), mas devido ao conjunto de produtos e/ou serviços oferecido.

Segundo esta teoria, há condutas que podem ser incentivadas pela criação de conglomerados, em especial pelo aumento do poder de portfólio. As principais condutas são tying e bundling. Tying corresponde à venda casada, isto é, a subordinação da aquisição de um produto ou serviço, à aquisição de outro produto ou serviço. Bundling ocorre quando os produtos são ofertados em conjunto e fazem parte de um item coeso como, por exemplo, a aquisição de microcomputador que inclui monitor, softwares pre-instalados, teclado, entre outros. Há também o bundling puro e o misto ${ }^{16}$. O primeiro ocorre quando produtos só podem ser comercializados em conjunto, em proporções fixas. O bundling misto, por sua vez, permite a oferta dos produtos de forma separada, mas o preço pela solução integrada é significativamente inferior. (Obs: os desdobramentos dessas condutas serão explicitadas na subseção 3.2).

(b) Consolidação do poder econômico (Entrenchment Doctrine)

15 Consultar Binotto (2018, p. 52 a 56) e Bundeskartellamt (2006, p. 3-5).

16 OECD (2008), Guidelines on the assessment of non-horizontal mergers under the Council Regulation on the control of concentrations between undertakings, p. 22 
A doutrina da "Consolidação do poder econômico" sustenta que danos concorrenciais decorrem do aumento do poder econômico resultante da operação conglomerada, particularmente em termos de poder financeiro e a consolidação pelo uso de marcas comerciais. Primeiramente, haveria a redução da atividade concorrencial de competidores tendo em vista a potencial ameaça da prática de preços predatórios ou outras medidas retaliatórias por parte da empresa dominante. Tais expectativas tem o poder dissuasório da não entrada de outras empresas no mercado, o que representa uma barreira adicional à entrada no mercado.

Há autores como Lim (2017, p. 51) que destacam efeitos deep pockets no âmbito desta teoria, ou seja, a capacidade de empresas exercerem práticas de mercado (e.g., preços predatórios por meio de subsídios cruzados) em tal escala que não podem ser acompanhadas por seus concorrentes em virtude do poder econômico.

(c) Redução da concorrência potencial (Substantial lessening of competition)

Esta teoria está relacionada à possibilidade de um AC resultar na diminuição da concorrência potencial sob duas variantes: (i) a diminuição da concorrência potencial percebida, e (ii) a diminuição da concorrência potencial real.

A concorrência potencial percebida se traduz quando o adquirente é previamente percebido pelos competidores estabelecidos como um entrante potencial, o que leva os competidores estabelecidos a atuarem de forma mais competitiva, ou seja, se privando de exercerem poder de mercado no intuito de desincentivar a entrada do novo player.

A doutrina da entrada potencial real, por sua vez, sustenta que, mesmo que uma fusão não tenha gerado efeitos imediatos na competição do mercado alvo, ela deveria ser impugnada, pois a empresa adquirente poderia e provavelmente teria entrado no mercado alvo de uma forma mais competitiva, seja por meio de investimentos próprios, seja ou pela aquisição de uma empresa menor ${ }^{17}$.

(d) Aumento da concentração agregada

Segundo esta teoria, a avaliação de efeitos conglomerados sustenta-se na identificação de efeitos nefastos decorrentes do aumento da concentração agregada de maneira transversal na economia de um país. Sob esse enfoque, não há necessidade de demonstrar possíveis danos à concor-

17 Há 2 importantes precedentes na jurisprudência norte-americana que exemplificam a aplicação da teoria relativa à concorrência potencial. O primeiro - United States v. Falstaff Brewing - Corp.(1973) -, a Suprema Corte Americana condenou a operação pela qual a Falstaff, que era a quarta maior cervejaria do país, pretendia adquirir a maior cervejaria de New England (Narragansett Brewing Co.), mercado no qual ainda não atuava. Nesse caso, a Suprema Corte afirmou que a concorrência potencial deveria ser apurada não pela análise da probabilidade ou dos possiveis planos de um agente (adquirente ou adquirido) entrar no mercado, mas sim pela verificação se as empresas atuantes no mercado acreditam/têm a percepção de que tal agente pode entrar no mercado. Assim, os atuais concorrentes poderiam atuar de maneira competitiva, ou se privar de exercer poder de mercado, para evitar que isso sirva de incentivo para a entrada. O outro caso é o FTC v. Procter and Gamble Co. (1967), no qual a Suprema Corte declarou ilegal a operação por meio da qual a P\&G, que atuava em vários mercados de produtos de limpeza (mas não no de alvejantes), pretendia adquirir a Clorox, marca de alvejantes líder no mercado americano. No caso, em razão do seu tamanho, do seu portfólio e do histórico de comportamento da empresa, a Suprema Corte considerou que a P\&G era o entrante mais provável no mercado. A teoria exposta no caso United States v. Falstaff Brewing Corp. ficou conhecida como a perceived potential entrant doctrine (doutrina da entrada potencial percebida), enquanto aquela utilizada no caso FTC v. Procter and Gamble Co. é conhecida como actual potencial entrant doctrine (doutrina da entrada potencial real). Consultar Parecer SG no 25/2016 (SEI 0273081), relativo ao AC BVMF/Cetip (vide Anexo). 
rência em mercados individualizados. Ao contrário, o aumento da concentração agregada justifica uma intervenção da autoridade antitruste.

CHENG (2017) enfatiza a importância de se avaliar o domínio de conglomerados, em especial nas economias pequenas e emergentes, visto que são menos dinâmicas e mais propensas a conglomerações, dadas as limitações de tamanho do mercado. Resumidamente, o autor aborda questões como regulação direta relativa ao tamanho de conglomerados, aplicação da legislação de defesa da concorrência no que tange a condutas anticoncorrenciais, diferenças entre poder de monopólio e poder econômico conglomerado, a natureza durável de conglomerados em comparação a monopólios, entre outras.

\subsection{Jurisprudência}

Ao analisar a jurisprudência do Cade quanto aos possiveis danos potenciais decorrentes de operações com efeitos conglomerados, verifica-se que a teoria do dano mais comumente utilizada pela Autarquia é a chamada teoria da atuação transversal (reciprocity dealings). Conforme definido anteriormente, a atuação transversal ocorre quando uma empresa emprega seu poder sobre determinado mercado para induzir ou alavancar sua atuação em outros mercados, em especial quando se trata de bens ou serviços complementares ou relacionados.

No contexto da teoria da atuação transversal, há condutas que podem ser incentivadas pela criação de conglomerados, em especial pelo aumento do poder de portfólio. As principais são tying e bundling.

As práticas de tying ou bundling não são, por si só, anticompetitivas, conforme destacado por alguns Conselheiros ${ }^{18}$ e podem implicar a oferta de produtos, serviços ou soluções integradas em condições mais benéficas aos consumidores, ao considerar a possibilidade de repasse ao consumidor de economias de escopo decorrentes de otimização de custos, por exemplo, com marketing, no processo de produção dos bens e/ ou serviços ou com fornecedores.

No entanto, caso não ocorram economias de escopo na fusão, as práticas tying ou bundling podem ser caracterizadas como práticas exclusionárias ou de fechamento de mercado. Isso porque a redução de preços por meio de venda casada dos bens e/ou serviços não terá sido feita de forma sustentada no longo prazo, o que poderá levar a empresa fusionada a impor preços mais elevados no longo prazo, recuperando, assim, suas perdas no curto prazo.

Acrescente-se que o fechamento não se dá apenas no mercado no qual há posição dominante por parte da empresa fusionada, mas também pode se estender a mercados adjacentes, sobretudo quando se identificam efeitos de rede.

Condutas exclusionárias desse tipo só são possíveis se a empresa puder exercer poder de mercado e se houver elevadas barreiras à entrada. Com isso, o problema principal quanto a efeitos conglomerados é, além da exclusão de competidores atuais (via preço predatório ou venda casada),

18 Vide voto do Conselheiro Relator no caso Bayer/Monsanto. Ato de Concentração n 08700.001097/2017-49 (Requerentes: Bayer Aktiengesselschaft e Monsanto Company). Conselheiro-Relator: Paulo Burnier da Silveira. Decisão: operação aprovada com restrições (remédios estruturais e comportamentais) em 16/02/2018 
a eliminação da concorrência potencial por meio de fechamento de mercado para possíveis entrantes.

Além das condutas unilaterais potencializadas pelos efeitos conglomerados, a exclusão de concorrentes e fechamento de mercado podem, também, aumentar a probabilidade do surgimento de condutas tácitas colusivas, ou seja, de efeitos coordenados, tendo em vista a redução do número de agentes atuantes no mercado.

Há vários casos na jurisprudência do Cade que, na análise de poder de portfólio em atos de concentração, argumenta-se a possibilidade de fechamento de mercado decorrente de tying e bundling. Destacam-se os seguintes atos de concentração: Danaher/General Eletric, Saint Gobain/ Rockfibras, Bayer Monsanto, Weg/TGM, Tigre/Condor e Ticket/Itaú19. Entre essas operações, o potencial exercício de poder coordenado de mercado foi constatado nos casos Ticket/Itaú e Tigre/Condor.

Além dos argumentos baseados na teoria da atuação transversal, outros aspectos relativos aos efeitos conglomerados têm sido abordados pelo Cade. A título de exemplo, nos atos de concentração Bayer/Monsanto, Itaú/XP e Ticket/Itaú foram expedidos votos que ressaltaram, entre outros aspectos, o gigantismo dos grupos econômicos envolvidos, o grau de concentração de setores econômicos e a eliminação de concorrentes atuais e potenciais com características disruptivas, com grande potencial de crescimento.

No tocante ao caso Bayer/Monsanto, o voto vogal do Conselheiro João Paulo de Resende ressalta, como consequência da operação, além do risco de práticas como tying, bundling e lock in, o gigantismo da Bayer no mercado de biotecnologia agrícola, em especial, no mercado de soja. Esses, segundo ele, são os verdadeiros problemas do AC, conforme transcrito abaixo:

Com um virtual monopólio em alguns mercados de sementes transgênicas, como a soja, e com um poder absoluto em mercados críticos de defensivos agrícolas, em especial os voltados para enfrentamento da ferrugem asiática, como bem destacou a patrona das terceiras interessadas, a empresa resultante desta operação ditará a capacidade e eficiência produtiva da soja brasileira. Uma de nossas principais fontes geradoras de divisas estaria nas mãos de uma única empresa, de um único país. Ou seja, as repercussões econômicas vão muito além do que poderia revelar à primeira vista uma análise clássica antitruste. Tem-se implicações, inclusive, de natureza geopolítica. Não por acaso, o mercado brasileiro de soja tem sido motivo de preocupação não só nossa, mas também da autoridade da concorrência da União Europeia, dado o volume do produto exportado para o continente europeu. (AC no 08700.001097/2017-49, Voto vogal do Conselheiro João Paulo

19 Atos de Concentração nos 08700.004203/2019-16 (Requerentes: Danaher Corporation e General Electric Company), aprovado sem restrições em 04/11/2019; 08700.04162/2018-79 (Requerentes: Saint-Gobain do Brasil Produtos Industriais e para Construção Ltda. e Rockfibras do Brasil Indústria e Comércio Ltda.), impugnado pela Superintendência-Geral e, em seguida, operação extinta por desistência das partes em 14/05/2019; 08700. 001097/2017-49 (Requerentes: Bayer Aktiengesellschaft e Monsanto Company), aprovado com restrições em 16/02/2018; 08700.008483/2016-81 (Requerentes: WEG Equipamentos Elétricos S/A e TGM Indústria e Comércio de Turbinas e Transmissões Ltda.), aprovado com restrições em 06/03/2018; 08700.009988/2014-09 (Requerentes: Tigre S/A - Tubos e Conexões e Condor Pincéis Ltda.), reprovado em 09/09/2015; 08700.006345/2018-29 (Requerentes: Itaú Unibanco S/A e Ticket Serviços S/A), aprovado sem restrições em 02/07/2019 
Além disso, com relação ao crescente grau de concentração no setor agrícola, segundo o citado voto (SEI no 0440658, parágrafo 11), em 2013, havia grande preocupação do setor agrícola brasileiro de que o mercado de sementes transgênicas e de defensivos agrícolas estivesse concentrado em apenas seis empresas, as chamadas Gene Giants. A Syngenta foi adquirida pela Chemchina, a Dow e Dupont se fundiram, sendo que o pacote de desinvestimentos foi comprado por outra empresa ${ }^{20}$, e a Bayer adquire a Monsanto. Logo, há uma redução para três Gene Mega Giants. Ou seja, caminha-se para um mundo em que os mercados de produção de alimentos e outros produtos agrícolas estarão nas mãos de uma empresa ou dos EUA, ou da Alemanha ou da China. Por fim, o voto sugere remédios estruturais mais robustos para enfrentar riscos de exercício de poder vertical e de conglomerado.

Um outro tipo de abordagem quanto aos possiveis danos de uma fusão/aquisição conglomeral encontra-se na decisão do Cade referente ao AC Kroton/Estácio ${ }^{21}$ cujo voto-vogal do Conselheiro Gilvandro V. C. de Araújo, pela reprovação do caso, foi acompanhado pela maioria dos conselheiros.

Este caso tratou, além de sobreposições horizontais, no segmento ensino superior presencial e à distância, de extensão de mercado em que as requerentes ofertavam o mesmo produto - ensino superior de graduação e pós-graduação presencial e à distância - mas em mercados geográficos distintos por meio de multiunidades.

De acordo com o voto da Conselheira-Relatora, que determinou a aprovação do caso com restrições unilaterais, não havia problema relativo a preocupações conglomerais como possíveis condutas exclusionárias, colusão tácita ou eliminação de concorrente potencial. Problemas concorrenciais foram detectados na concentração horizontal, tanto nos cursos de graduação/pós-graduação EAD (ensino à distância) quanto na graduação/pós-graduação presencial; e, dentro de uma dinâmica competitiva e no âmbito da concorrência monopolística, no tocante à qualidade e à marca. (Vide AC no 006185/2016-56, Voto da Conselheira-Relatora Cristiane Alkmin (SEI no 0360385), parágrafo 486).

No entanto, o voto-vogal do Conselheiro Gilvandro V. C. de Araújo (SEI no 0357424, parágrafos 32, 33 e 42) ressalta o aspecto conglomeral da operação sob dois aspectos: o porte das Requerentes e a importância da marca.

No que tange à dimensão das Requerentes, o citado voto (SEI no 0357424, parágrafo 43) pontuou o crescimento por meio de aquisições que ambas as empresas, isoladamente, fizeram nos últimos anos. Contabilizou-se um total de 40 atos de concentração nos quais as Requerentes participaram, notificados e de não notificação obrigatória, no período de 2001 a 2017.

O voto destaca a dimensão da operação:

Está-se a formar um conglomerado de ensino, no qual o primeiro player nacional adquire o segundo para contar com presença em 109 municípios e

20 A empresa norte-americana FMC Corporation adquiriu parte significativa do negócio de proteção de culturas da DuPont; com a venda simultânea da FMC Heath \& Nutrition à DuPont. Consultar: https://www.dupont.com.br/news/dowduponttmconclui-transacao-da-dupont-com-a-fmc.html Acesso: 11/11/2020.

21 Ato de Concentração no 08700.006185/2016-56 (Requerentes: Kroton Educacional S/A e Estácio Participações S/A, reprovado em 12/07/2017. 
com 206 campi e centenas de milhares de alunos, com um enorme potencial anual de expansão de matrículas. Só que essa situação já havia acontecido também em Kroton/Anhanguera, em que, à época, o primeiro player também havia adquirido o segundo. (AC no 006185/2016-56, Voto do Conselheiro Gilvandro V. C. de Araújo (SEI no 0357424), parágrafo 43).

Com relação à marca, esta representa um elemento constitutivo de barreiras à entrada, de acordo com o referido voto (SEI no 0357424, parágrafo 29) Além das barreiras legais e regulatórias inerentes ao setor educacional, um dos pontos críticos da operação em relação à entrada diz respeito aos investimentos em publicidade e ao valor agregado às marcas detidas por Kroton e Estácio, o que também pode configurar uma significativa barreira à entrada para novos competidores e também uma dificuldade adicional à concorrência de agentes econômicos já estabelecidos. Em um cenário em que a marca representa uma significativa variável concorrencial, eventual entrante deveria arcar com investimentos adicionais para tornar sua marca aproximadamente tão conhecida quanto as marcas já estabelecidas.

Um outro exemplo que se destaca é o voto do Conselheiro-Relator em relação ao AC Ticket/Itaú. De acordo com citado voto, a operação apresentou: sobreposição horizontal no mercado de emissão de cartões de pagamento pré-pago; relação vertical nos mercados de vale-benefícios (upstream) e credenciamento e captura de transações (downstream). Verificou-se a possibilidade de acesso a informações sensiveis de concorrentes, de fechamento de mercado e de coordenação tácita com outros conglomerados. (Vide AC no 08700.006345/2018-29, Voto do Conselheiro-Relator João Paulo de Resende, SEI no 0632440, Ementa)

Na visão do Conselheiro-Relator (SEI no 0632440, parágrafos 38, 44), a operação reforça o poder conglomerado/portfólio do grupo adquirente com a entrada no mercado de vale-benefícios. Com relação ao poder conglomerado/portfólio do grupo adquirente, ou seja, Itaú/Unibanco, consta do voto do Conselheiro-Relator que o Itaú-Unibanco atua, direta ou indiretamente, em vários de setores da economia brasileira, em geral ligados a/ou derivados do mercado de transações financeiras, como diversos tipos de seguros, emissão de cartões de crédito, programas de fidelização, crédito consignado, planos de previdência privada, entre outros.

Especificamente com relação ao poder de portfólio, verifica-se, segundo o citado voto (SEI no 0632440, parágrafo 40) que esse poder decorre da própria atividade bancária do Itaú, cuja presença é constatada em vários mercados correlacionados, ainda que não verticalmente e cujos bens ou serviços podem ser transacionados conjuntamente, em pacote (bundling). De acordo com o Conselheiro, o setor bancário caracteriza-se por altos custos de transação de mudança de domicílio bancário (efeito lock-in) e que acaba sendo usado pelos bancos para associar ao serviço bancário básico de depósitos e saques, produtos e serviços acessórios e adicionais, como emissão de cartões de crédito, seguros, previdência privada, financiamentos os mais diversos, etc. Muitas vezes os bancos conferem descontos nos serviços bancários básicos e mesmo em outros serviços (cartão de crédito), a depender da quantidade de serviços acessórios consumidos pelo cliente (ou seja, um subsídio cruzado que viabiliza o empacotamento.

Além do Conselheiro-Relator utilizar argumentos (SEI no 0632440, parágrafos 51 e 98) como possibilidade de fechamento de mercado por meio de atuação transversal em outros mercados, ou 
seja, efeitos de concentração considerando bundles e spillovers em mercados adjacentes, enfatizou-se como preocupante, sob o ponto de vista concorrencial, o grau de concentração do setor bancário brasileiro e o tamanho dos principais players nesse setor que atuam em vários setores relacionados.

O voto (SEI 0632440, parágrafo 98) conclui que os bancos brasileiros produziram uma estrutura altamente concentrada em seu mercado original, e, não sendo mais admissivel qualquer concentração horizontal adicional nesse mercado, vêm avançando sobre mercados correlatos e adjacentes, reproduzindo alhures a estrutura oligopolizada do mercado bancário. O Conselheiro Relator destacou que o Grupo Itaú, entre 2016 e 2019, submeteu à análise do Tribunal, os seguintes atos de concentração sensiveis do ponto de vista concorrencial - Itaú/Mastercard, Itaú/Citigroup, Itaú/XP e Itaú/Ticket, ora em análise ${ }^{22}$. Os efeitos da operação são menor concorrência e maiores preços para os demais agentes econômicos, sejam consumidores diretos, sejam etapas intermediárias da cadeia produtiva.

Apesar da operação ter sido aprovada sem restrições, visto que o voto do Conselheiro Relator não foi acompanhado pela maioria do Tribunal, é importante destacar esse caso em virtude da existência de uma preocupação crescente por parte de representantes da autoridade antitruste com relação ao grau de concentração setor bancário brasileiro e do tamanho dos principais players, o que amplia os argumentos aplicados na análise de teorias do dano.

Um outro caso que merece menção é o citado AC Itaú/XP. Sob o enfoque da teoria do dano "substantial lessening of competition", um dos argumentos utilizados, em voto vogal ${ }^{23}$, relativos a efeitos conglomerados foi a eliminação de uma relevante concorrente. A XP foi considerada um agente maverick, pois ao utilizar tecnologias disruptivas, ou seja, plataformas de investimento abertas, vinha contribuindo para um processo de desbancarização, com o aumento da contestabilidade do setor bancário. A aquisição da XP por um grande player do setor financeiro - Itaú Unibanco S/A - iria não apenas diminuir a concorrência entre os atuais players, mas também a possibilidade de entrada no mercado de outras plataformas abertas de investimentos.

Na mesma linha de argumentação, a decisão, de aprovação com restrições, referente ao AC BM\&F/Cetip ${ }^{24}$ apresentou como problema concorrencial a eliminação da concorrência potencial, devido à dificuldade de acesso de terceiros à infraestrutura essencial detida pelas Requerentes, ou seja, os serviços de central depositária.

Nota-se, por conseguinte, que ao longo dos últimos anos tem-se ampliado as teorias do dano aplicadas aos julgamentos do Cade ao considerar aspectos como grau de concentração de setores econômicos - e.g., agrícola, bancário e de ensino superior-, eliminação da concorrência poten-

22 Atos de Concentração nos 08700.009363/2015-10 (Requerentes: Itaú Unibanco S/A e MasterCard Brasil Soluções de Pagamento Ltda., aprovado com restrições em 17/05/2016; 08700.001642/2017-05 (Requerentes: Itaú Unibanco S/A e Banco Citibank S/A), aprovado com restrições em 22/08/2017; 08700.004431/2017-16 (Requerentes: Itaú Unibanco S/A e XP Investimentos S/A), aprovado com restrições em 20/03/2018; 08700.006345/2018-29 (Requerentes: Itaú Unibanco S/A e Ticket Serviços S/A), aprovado sem restrições em 2/07/2019.

23 Voto vogal da Conselheira Cristiane Alkmin, que se posicionou pela reprovação do ato de concentração. Vide $A C$ no 08700.004431/2017-16, Voto-vogal (SEl no 0455496), parágrafos 67, 70 e 71. O AC foi aprovado com restrições nos termos do voto do Conselheiro-Relator em 20/03/2018 (SEI no 0455795).

24 Vide AC no 08700.004860/2016-11, Voto vogal vencedor do Conselheiro Paulo Burnier da Silveira (SEI no 0316888), parágrafos 2,3 e 4 . 
cial, consolidação do poder econômico via marca comercial no segmento de ensino superior, entre outros.

Por fim, um setor econômico que também merece menção é o de saúde. Especificamente, o mercado de saúde suplementar cuja cadeia produtiva é composta por 3 segmentos: planos de saúde, serviços hospitalares e serviços de medicina diagnóstica.

Nota-se, ao longo dos anos, mudanças estruturais no mercado de saúde suplementar: aumento da concentração ${ }^{25}$, mudanças em participações societárias ${ }^{26}$, intenso processo de integração vertical envolvendo operadoras de planos de saúde, hospitais e medicina diagnóstica, e ampliação na atuação em outros mercados relacionados como administração de beneficios, distribuição de medicamentos médico-hospitalares, distribuição de materiais de uso médico-hospitalar, radiofármacos, corretagem de seguros, desenvolvimento de softwares de gestão de saúde e outros serviços de TI direcionados à área da saúde, entre outros.

Constatam-se que são poucos os casos que o Cade analisou efeitos conglomerados no mercado de saúde suplementar. Porém, vale mencionar o AC Rede D’Or/Perinatal ${ }^{27}$, que embora não tenha apresentado uma teoria do dano, pois foi aprovado sem restrições, pode indicar um caminho para análises futuras de efeitos conglomerados dadas as mudanças neste setor.

O AC Rede D'Or/Perinatal tratou da aquisição pela Rede D'Or de maternidades da Perinatal localizadas no município do Rio de Janeiro, especificamente na Barra da Tijuca e Laranjeiras. 0 parecer da SG (SEI 0688048, parágrafos 134 a 177) analisou o poder de portfólio sob alguns aspectos como: (i) a existência ou não de opções de maternidades nas regiões de atuação da Perinatal; (ii)

25 Desde 2003 até 2020, o Cade julgou 233 atos de concentração relativos a empresas dos mercados de planos de saúde, hospitais e serviços de medicina diagnóstica. Houve o crescimento e a consolidação de alguns grupos econômicos que se tornaram líderes dos seus mercados, adotando como uma de suas principais estratégias de expansão, operações de fusão e aquisição de empresas. Rede D'Or, Amil, Dasa, Notre Dame Intermédica, Fleury, Unimed e Qualicorp, nessa ordem, são as empresas mais ativas nessas operações, concentrando 72,43\% dos casos. Acrescente-se que entre 2018 a 2020, o Grupo Rede D'Or foi o que mais se destacou em termos de fusões/aquisições: foram 19 atos de concentrações nesse período, seguido do grupo Notre Dame Intermédica com 11 atos de concentração e Dasa, com 6. Fonte: “Cadernos do Cade: Atos de concentração nos mercados de planos de saúde, hospitais e medicina diagnóstica" e Sistema SEl/Cade Acesso: 06/09/2021.

26 A título de exemplo, vale mencionar a ligação entre dois importantes grupos - Rede D'Or e Qualicorp, um dos líderes no mercado de administração de benefícios. Por meio do AC no 08700.004185/2019-64 (Requerentes: Rede D'Or São Luiz S/A, José Seripieri Filho), aprovado sem restrições em 17/10/2019, a Rede D'Or adquiriu participação minoritária de 10\% do capital social e votante da Qualicorp. Posteriormente, o AC 08700.004830/2020-82 (Requerentes: Rede D'Or São Luiz S/A e Qualicorp Consultoria e Corretora de Seguros S/A), aprovado sem restrições em $04 / 11 / 2020$, tratou de eventual aumento de participação da Rede D'Or na Qualicorp por meio da possivel aquisição de ações em bolsa de valores. Argumentou-se, na análise de ambos atos de concentração, que a referida participação não implicaria acesso da Rede D'Or a informações concorrencialmente sensiveis a respeito das negociações de seus concorrentes no setor de cuidados à saúde com operadoras de planos de saúde. Atualmente os principais acioniastas da Qualicorp são: Rede Rede D’Or São Luiz S/A (25,51\%), Pátria Investimentos (15,06\%), e Opportunity (7,44\%). Consultar em: Qualicorp | Relações com Investidores Acesso: 07/09/2021. Outra participação societária que merece menção é a participação do Grupo Bradesco no Laboratório Fleury cujo maior acionista é a Bradseg Participações S/A (controlada pelo Banco Bradesco) Fonte: http://bvmf.bmfbovespa.com.br/cias-listadas/empresas-listadas/ ResumoEmpresaPrincipal.aspx?codigoCvm=21881\&idioma=pt-br. Acesso em 07/09/2021. Ademais, o Grupo Bradesco detém a Bradesco Saúde S/A, a maior operadora de planos de saúde em dezembro de 2020, com 3.296 .785 beneficiários e a Odontoprev, líder no mercado de planos de saúde exclusivamente odontológicos, com 6.565 .609 beneficiários em dezembro de 2020. Fonte: Sistema Tabnet/ANS. Acesso: 05/04/2021.

27 AC no 08700.003245/2019-21 (Requerentes: Rede D’Or São Luiz S/A e Casa de Saúde Laranjeiras Ltda., Unidade Neonatal da Lagoa Ltda. e Cia de Serviços Especiais e Unificados Ltda.), aprovado sem restrições em 17/12/2019. 
se realmente existe relação de dependência das operadoras de planos de saúde (OPS) em relação à Perinatal; (iii) se a operação efetivamente gera incremento relevante de poder de barganha para a Rede D'Or em negociações com as OPS; e (iv) se a operação aumenta a probabilidade de adoção de comportamentos abusivos da Rede D'Or nessas negociações. Resumidamente, concluiu-se, após instrução realizada junto a operadoras de planos de saúde, que o poder de barganha da Rede D'Or junto a OPS é limitado dada a sua estrutura não verticalizada e a extrema relevância das OPS no total de sua receita.

Um outro caso relacionado ao segmento de saúde, mas não propriamente de saúde suplementar, é o AC Dabi/Gnatus ${ }^{28}$ relativo a equipamentos odontológicos. Neste caso, aprovado com restrições, o parecer da SG (SEI 0093318, parágrafos 249,296 ) ressaltou a possibilidade de abuso de poder de mercado advindo do grande poder de portfólio das Requerentes, o que aumenta a dificuldade de contestação de rivais, em especial, pequenos fabricantes e novos entrantes. 0 parecer especificou a possibilidade de aumento de preços, por exemplo, de bombas a vácuo e/ou raio X intraoral em função da facilidade, por parte dos consumidores, de continuar adquirindo todos os produtos de uma mesma marca e, muitas vezes, em um mesmo ponto de venda.

\subsection{Análises econômicas}

As operações conglomerais analisadas pelo Cade têm sido, em alguns casos, declaradas complexas, por meio de despachos expedidos pela SG. Com o respaldo de notas técnicas feitas pela SG, a declaração de complexidade tem exigido diligências complementares como, por exemplo: apresentação, por parte das Requerentes, de eficiências econômicas geradas pelo ato de concentração; aprofundamento da análise de entrada, rivalidade e exercício de poder coordenado; elaboração, por parte do DEE, de estudos quantitativos a respeito de impactos concorrenciais decorrentes da operação; análises de pareceres econômicos apresentados pelas Requerentes, entre outras.

Vale mencionar, resumidamente, as notas técnicas elaboradas pelo DEE no período em questão e que, em geral, tratou de atos de concentração declarados complexos pela SG. As notas técnicas do DEE têm utilizado tanto análises quantitativas quanto qualitativas, conforme se verifica na tabela a seguir.

28 AC no 08700.001437/2015-70 (Requerentes: Dabi Atlante S/A Indústrias Médico-Odontológica e Gnatus Equipamentos Médico-Odontológicos Ltda.), aprovado com restrições em 02/12/2015. 
Tabela I - Análises econômicas em operações conglome

\begin{tabular}{|c|c|c|c|}
\hline Ato de concentração & $\begin{array}{l}\text { Objetivo da análise } \\
\text { econômica }\end{array}$ & Metodologia & Conclusão DEE \\
\hline \multirow[t]{2}{*}{$\begin{array}{l}\text { 08700.004162/2018- } \\
79 \text { (Requerentes: } \\
\text { Saint-Gobain do Brasil } \\
\text { Produtos Industriais e } \\
\text { para Construção Ltda. } \\
\text { e Rockfibras do Brasil } \\
\text { Indústria e Comércio Ltda) } \\
\text { NT DEE no 5/2019 (SEI } \\
\text { 0602455) }\end{array}$} & $\begin{array}{l}\text { Analisar aspectos sobre } \\
\text { mercado relevante, } \\
\text { rivalidade e poder de } \\
\text { barganha. }\end{array}$ & $\begin{array}{l}\text { Elaboração de cenários, } \\
\text { do ponto de vista } \\
\text { concorrencial, por meio } \\
\text { de tratamento dos dados } \\
\text { (software R - pacote } \\
\text { ggplot2) }\end{array}$ & $\begin{array}{l}\text { Não houve elementos para } \\
\text { justificar alterações na } \\
\text { delimitação de mercado } \\
\text { relevante proposta pela } \\
\text { SG. Não foram encontradas } \\
\text { evidências da existência } \\
\text { alegada pelas requerentes } \\
\text { de rivalidade e poder de } \\
\text { barganha, que pudessem }\end{array}$ \\
\hline & & & $\begin{array}{l}\text { mitigar os riscos } \\
\text { concorrenciais } \\
\text { identificados durante a } \\
\text { instrução do processo. } \\
\text { Tampouco houve } \\
\text { elementos concretos } \\
\text { apresentados que } \\
\text { justificassem a aceitação } \\
\text { das alegações de eficiência. } \\
\text { Vide NT DEE no 5/2019 } \\
\text { (SEI 0602455), § 4ㅇ e 50 da } \\
\text { Conclusão. }\end{array}$ \\
\hline $\begin{array}{l}\text { 08700.006345/2018- } \\
29 \text { (Requerentes: Itaú } \\
\text { Unibanco S/A e Ticket } \\
\text { Serviços S/A) } \\
\text { NT DEE no 20/2019 (SEI } \\
\text { 0622418) }\end{array}$ & $\begin{array}{l}\text { Quantificar os incentivos } \\
\text { para o fechamento de } \\
\text { mercado decorrente } \\
\text { de integrações verticais } \\
\text { entre mercados de vale- } \\
\text { benefícios (upstream) } \\
\text { e credenciamento e } \\
\text { captura de transações } \\
\text { (downstream). Além } \\
\text { disso, buscou-se avaliar a } \\
\text { possibilidade de aumento } \\
\text { do exercício de poder } \\
\text { coordenado no mercado } \\
\text { de cartões de pagamento }\end{array}$ & $\begin{array}{l}\text { (i) Análise de breakeven } \\
\text { em recusa de negociação } \\
\text { com transbordamento, e } \\
\text { (ii) modelo de aritmética } \\
\text { vertical, método utilizado } \\
\text { para quantificar os } \\
\text { incentivos a fechamento } \\
\text { de mercado pós-operação. }\end{array}$ & $\begin{array}{l}\text { Encontrados indícios } \\
\text { quantitativos e qualitativos } \\
\text { da existência de incentivos } \\
\text { para o fechamento de } \\
\text { mercado e possibilidade } \\
\text { de aumento do exercício } \\
\text { de poder coordenado } \\
\text { nos mercados alvo da } \\
\text { operação. Sugerida a } \\
\text { avaliação de remédios } \\
\text { comportamentais para } \\
\text { mitigar os potenciais } \\
\text { efeitos lesivos à } \\
\text { concorrência. Vide NT DEE } \\
\text { no 20/2019 (SEI 0622418), } \\
\text { Ementa. }\end{array}$ \\
\hline
\end{tabular}




\begin{tabular}{|c|c|c|c|}
\hline Ato de concentração & $\begin{array}{l}\text { Objetivo da análise } \\
\text { econômica }\end{array}$ & Metodologia & Conclusão DEE \\
\hline $\begin{array}{l}\text { 08700.004446/2017- } \\
84 \text { Essilor International } \\
\text { (Compagnie Générale } \\
\text { d'Optique) S/A (Essilor) } \\
\text { e Luxottica Group S.p.A. } \\
\text { (Luxottica) } \\
\text { Obs: não há NT } \\
\text { DEE - houve uma } \\
\text { contribuição do DEE, por } \\
\text { meio da análise de dados } \\
\text { do setor, ao Parecer SG (SEI } \\
\text { 0445156), § } 194 \text { a } 208 .\end{array}$ & $\begin{array}{l}\text { Analisar se há evidências } \\
\text { de adoção de alguma } \\
\text { política de diferenciação } \\
\text { de preços, por parte da } \\
\text { Essilor, aos clientes que } \\
\text { adquirem suas máquinas }\end{array}$ & $\begin{array}{l}\text { Análise de dados } \\
\text { disponibilizados pelas } \\
\text { Requerentes (ex: dados de } \\
\text { vendas, preço médio, perfil } \\
\text { de cliente, descontos, } \\
\text { entre outros). }\end{array}$ & $\begin{array}{l}\text { Não foram encontradas } \\
\text { evidências que a } \\
\text { adquirente esteja } \\
\text { adotando práticas } \\
\text { discriminatórias de } \\
\text { preços. Tais conclusões se } \\
\text { baseiam em uma análise } \\
\text { preliminar e limitada } \\
\text { realizada pela SG ao longo } \\
\text { da instrução do presente } \\
\text { ato de concentração com } \\
\text { o objetivo de avaliar se } \\
\text { práticas pré-existentes } \\
\text { poderiam ser estendidas } \\
\text { para outros mercados } \\
\text { após a operação, devendo } \\
\text { a avaliação pertinente às } \\
\text { condutas pré-existentes } \\
\text { e seus possíveis efeitos } \\
\text { anticompetitivos ser } \\
\text { realizada em procedimento } \\
\text { específico por meio do } \\
\text { controle de condutas. Vide } \\
\text { Parecer SG (SEI 0445156), } \\
\S 208\end{array}$ \\
\hline $\begin{array}{l}\text { 08700.001097/2017- } \\
49 \text { (Requerentes: Bayer } \\
\text { Aktiengesellschaft (Bayer) } \\
\text { e Monsanto Company } \\
\text { (Monsanto)) } \\
\text { NT DEE no 33/2017 (SEI } \\
\text { 0393512) }\end{array}$ & $\begin{array}{l}\text { Avaliar eventual redução } \\
\text { de incentivos à inovação }\end{array}$ & $\begin{array}{l}\text { A análise baseou-se } \\
\text { nos principais achados } \\
\text { empíricos da literatura } \\
\text { sobre os determinantes } \\
\text { da inovação e análise } \\
\text { da decisão da Comissão } \\
\text { Europeia no caso Dow- } \\
\text { DuPont, em que houve } \\
\text { preocupações relativas à } \\
\text { questão da inovação. }\end{array}$ & $\begin{array}{l}\text { Em meio à ausência de } \\
\text { subsídios teóricos ou } \\
\text { empíricos suficientes, } \\
\text { não é possível descartar } \\
\text { eventuais impactos nocivos } \\
\text { da operação com relação } \\
\text { à inovação do mercado e/ } \\
\text { ou das Requerentes. Vide } \\
\text { NT DEE no } 33 / 2017 \text { (SEl } \\
\text { 0393512), Ementa. }\end{array}$ \\
\hline
\end{tabular}




\begin{tabular}{|c|c|c|c|}
\hline Ato de concentração & $\begin{array}{l}\text { Objetivo da análise } \\
\text { econômica }\end{array}$ & Metodologia & Conclusão DEE \\
\hline $\begin{array}{l}\text { 08700.006185/2016-56 } \\
\text { (Requerentes: Kroton } \\
\text { Educacional S/A e Estácio } \\
\text { Participações S/A } \\
\text { NT DEE no 7/2017 (SEI } \\
\text { 0298652) }\end{array}$ & $\begin{array}{l}\text { Avaliar a importância da } \\
\text { marca e dos investimentos } \\
\text { em marketing/publicidade } \\
\text { no mercado de ensino à } \\
\text { distância (EAD) e examinar } \\
\text { a existência de relações } \\
\text { entre os mercados } \\
\text { presencial e a distância de } \\
\text { ensino superior }\end{array}$ & $\begin{array}{l}\text { Análise econométrica Diff- } \\
\text { in-Diff; análise de preços } \\
\text { hedônicos }\end{array}$ & $\begin{array}{l}\text { a) A importância da } \\
\text { marca e a necessidade } \\
\text { de investimentos em } \\
\text { marketing/publicidade } \\
\text { constituem importantes } \\
\text { barreiras à entrada ao } \\
\text { mercado em questão; } \\
\text { b) a atuação no ensino } \\
\text { presencial facilita a atração } \\
\text { de alunos no ensino à } \\
\text { distância, revelando a } \\
\text { forte relação entre as } \\
\text { duas modalidades; e c) } \\
\text { que a operação tiraria } \\
\text { do mercado um player } \\
\text { importante com marca } \\
\text { consolidada e capacidade } \\
\text { de investimento em } \\
\text { propaganda e marketing, } \\
\text { que tem contribuído para } \\
\text { aumento da rivalidade } \\
\text { entre as empresas, ao } \\
\text { adotar estratégia de preços } \\
\text { baixos. Vide NT DEE no } \\
7 / 2017 \text { (SEI 0298652), § 9o }\end{array}$ \\
\hline $\begin{array}{l}\text { 08700.004860/2016- } \\
11 \text { (Requerentes: } \\
\text { BM\&FBovespa S/A - Bolsa } \\
\text { de Valores, Mercados e } \\
\text { Futuros (BVMF), Cetip S/A } \\
\text { - Mercados Organizados } \\
\text { (Cetip)) } \\
\text { NT DEE no 38/2016 (SEI } \\
0271907\end{array}$ & $\begin{array}{l}\text { Analisar as eficiências da } \\
\text { operação }\end{array}$ & $\begin{array}{l}\text { A análise qualitativa } \\
\text { do estudo de eficiência } \\
\text { apresentado pelas } \\
\text { Requerentes baseou-se } \\
\text { em: doutrina econômica, } \\
\text { jurisprudência do Cade e } \\
\text { de outras jurisdições, Guia } \\
\text { H do Cade, outros estudos } \\
\text { que contrapõem a visão } \\
\text { das Requerente. }\end{array}$ & $\begin{array}{l}\text { Não aceitação das alegadas } \\
\text { eficiências - as eficiências } \\
\text { de custos fixos estimadas } \\
\text { possuem vários problemas } \\
\text { conceituais. As eficiências } \\
\text { foram expostas de forma } \\
\text { ampla e genérica. Vide } \\
\text { NT DEE no 38/2016 (SEI } \\
\text { 0271907), Ementa. }\end{array}$ \\
\hline
\end{tabular}




\begin{tabular}{|c|c|c|c|}
\hline Ato de concentração & $\begin{array}{l}\text { Objetivo da análise } \\
\text { econômica }\end{array}$ & Metodologia & Conclusão DEE \\
\hline $\begin{array}{l}\text { 08700.003462/2016-79 } \\
\text { (Requerentes: Reckitt } \\
\text { Benckiser (Brasil) Ltda. e } \\
\text { Hypermarcas S/A } \\
\text { NT DEE no 30/2016 (SEI } \\
\text { 0226953) }\end{array}$ & $\begin{array}{l}\text { Avaliar possíveis aumentos } \\
\text { de preços decorrentes da } \\
\text { operação. }\end{array}$ & $\begin{array}{l}\text { Metodologia de screening } \\
\text { UPP e GUPPI; simulação de } \\
\text { fusão por meio do modelo } \\
\text { PC AIDS. }\end{array}$ & $\begin{array}{l}\text { No que tange ao mercado } \\
\text { de lubrificantes íntimos } \\
\text { constatou-se uma pressão } \\
\text { de aumento de preços, a } \\
\text { partir da metodologia de } \\
\text { screening UPP e GUPPI, e } \\
\text { aumentos consideráveis } \\
\text { de preços na simulação } \\
\text { de fusão usando o } \\
\text { modelo PC AIDS. Sugere- } \\
\text { se que existem efeitos } \\
\text { anticompetitivos no } \\
\text { mercado de lubrificantes } \\
\text { íntimos pós-operação. } \\
\text { Já para o mercado de } \\
\text { preservativos masculinos } \\
\text { não se detectou pressão } \\
\text { significativa nos preços a } \\
\text { partir dos indicadores UPP } \\
\text { e GUPPI, e, analogamente, } \\
\text { não houve grandes } \\
\text { variações dos mesmos na } \\
\text { análise de simulação de } \\
\text { fusão, PC AIDS. Conclui- } \\
\text { se que a operação não } \\
\text { apresenta grande risco } \\
\text { à competitividade no } \\
\text { mercado de preservativos } \\
\text { masculinos. Vide NT DEE } \\
\text { no } 30 / 2016 \text { (SEl 0226953), } \\
\text { Ementa. }\end{array}$ \\
\hline \multirow[t]{2}{*}{$\begin{array}{l}\text { 08700.001437/2015-70 } \\
\text { Requerentes: Dabi Atlante } \\
\text { S/A Indústrias Médico- } \\
\text { Odontológica e Gnatus } \\
\text { Equipamentos Médico- } \\
\text { Odontológicos Ltda. } \\
\text { NT DEE no 31/2015 (SEI } \\
\text { 009132) }\end{array}$} & $\begin{array}{l}\text { Apresentar testes } \\
\text { que caracterizam o } \\
\text { mercado em que as } \\
\text { requerentes operam e } \\
\text { tentar definir a relação } \\
\text { de substitutibilidade com } \\
\text { empresas concorrentes }\end{array}$ & $\begin{array}{l}\text { Teste sobre a distribuição } \\
\text { de preços (teste } \\
\text { Kolmogorov-Smirnov), } \\
\text { modelos de simulações } \\
\text { - AIDS (Almost Ideal } \\
\text { Demand System). }\end{array}$ & $\begin{array}{l}\text { Há diferenciação nos } \\
\text { mercados estudados por } \\
\text { meio das distribuições de } \\
\text { preço e apresentou-se } \\
\text { um modelo de simulação } \\
\text { de fácil implementação } \\
\text { em virtude do número de } \\
\text { produtos. Verificaram-se }\end{array}$ \\
\hline & & & $\begin{array}{l}\text { eficiências altas e } \\
\text { significativos aumentos } \\
\text { de preço nos mercados } \\
\text { de: raio-X intraoral; } \\
\text { profilaxia; bomba a vácuo } \\
\text { e consultórios, exceto na } \\
\text { versão com Nests. Vide } \\
\text { NT DEE no } 31 / 2015 \text { (SEl } \\
\text { 0091323), Considerações } \\
\text { finais: §§ 10 e 2o }\end{array}$ \\
\hline
\end{tabular}




\begin{tabular}{|c|c|c|c|}
\hline Ato de concentração & $\begin{array}{l}\text { Objetivo da análise } \\
\text { econômica }\end{array}$ & Metodologia & Conclusão DEE \\
\hline $\begin{array}{l}\text { 08700.009988/2014-09 } \\
\text { (Requerentes: Tigre S/A - } \\
\text { Tubos e Conexões (Tigre) e } \\
\text { Condor Pincéis Ltda.) } \\
\text { Obs: o DEE expediu } 2 \\
\text { notas técnicas: NT DEE no } \\
\text { 19/2015 (SEI 0056002); } \\
\text { NT DEE no 35/2015 (SEI } \\
\text { 0094537) }\end{array}$ & $\begin{array}{l}\text { - Avaliar possíveis } \\
\text { aumentos de preços } \\
\text { decorrentes da operação } \\
\text { (NT DEE no19/2015) } \\
\text { - Analisar o estudo de } \\
\text { eficiências apresentado } \\
\text { pelas Requerentes. (NT } \\
\text { DEE no 35/2015) }\end{array}$ & $\begin{array}{l}\text { Simulação PCAIDS (NT DEE } \\
\text { no 19/2015 e NT DEE no- } \\
\text { 35/2015) }\end{array}$ & $\begin{array}{l}\text { Há possibilidade de se } \\
\text { verificar elevações de } \\
\text { preços nos mercados } \\
\text { analisados, caso não } \\
\text { existam eficiências } \\
\text { associadas à presente } \\
\text { operação. Estas conclusões } \\
\text { poderão ser melhor } \\
\text { desenvolvidas, caso as } \\
\text { partes apresentem estudos } \\
\text { de eficiências ao SBDC } \\
\text { e apresentem dados } \\
\text { com maiores detalhes. } \\
\text { Vide NT DEE no 19/2015 } \\
\text { (SEI 0056002), item 3. } \\
\text { Conclusão, §10 . } \\
\text { A simulação demonstra } \\
\text { que haverá aumento } \\
\text { de preços no momento } \\
\text { pós operação, mesmo } \\
\text { assumindo níveis de } \\
\text { eficiência alegados pelas } \\
\text { Requerentes. Vide NT DEE } \\
\text { no } 35 / 2015 \text { (SEl 0094537), } \\
\text { item 2.3 Eficiências, } \\
\text { subitem Simulação. }\end{array}$ \\
\hline $\begin{array}{l}\text { 08700.005447/2013-12 } \\
\text { Requerentes: Kroton } \\
\text { Educacional S/A e } \\
\text { Anhanguera Educacional } \\
\text { Participações S/A } \\
\text { NT DEE no 6/2014 (SEI }\end{array}$ & $\begin{array}{l}\text { Analisar (i) modelo de } \\
\text { precificação EAD da } \\
\text { Kroton e da Anhanguera; } \\
\text { (ii) importância da } \\
\text { marca nesse segmento; } \\
\text { e iii) a diminuição da } \\
\text { concorrência potencial } \\
\text { entre as Requerentes; e } \\
\text { (iv) possíveis eficiências } \\
\text { relativas ao AC. }\end{array}$ & $\begin{array}{l}\text { Análise qualitativa baseada } \\
\text { em: doutrina econômica, } \\
\text { jurisprudência do Cade, } \\
\text { jurisprudência em } \\
\text { outras jurisdições, dados } \\
\text { disponibilizados pelas } \\
\text { Requerentes, dados do } \\
\text { setor, entre outros. }\end{array}$ & $\begin{array}{l}\text { A operação resultaria, } \\
\text { certamente, em uma } \\
\text { empresa líder de mercado, } \\
\text { com marcas amplamente } \\
\text { reconhecidas e com } \\
\text { poder de investimento em } \\
\text { propaganda e marketing } \\
\text { superior ao dos demais } \\
\text { concorrentes, o que } \\
\text { aumenta barreiras à } \\
\text { entrada. Com relação às } \\
\text { eficiências, verificou que } \\
\text { inexiste um nexo claro } \\
\text { de causalidade entre os } \\
\text { benefícios alegados pelas } \\
\text { requerentes e o ato de } \\
\text { concentração. Vide NT DEE } \\
\text { no } 6 / 2014 \text { (SEI 0018929), } \\
\text { volume } 16, \S \S .96,97 \text { e } \\
161 .\end{array}$ \\
\hline
\end{tabular}

Fonte: elaboração própria 


\section{EFEITOS CONGLOMERADOS NA ERA DIGITAL}

Em setembro de 2019 o Cade lançou BRICS in the Digital Economy - Competition Policy in Practice, o primeiro relatório das autoridades de defesa dos países do BRICS - no âmbito do Grupo de Trabalho Research on the Competition Issues in the Digital Markets (pesquisa em assuntos da concorrência em mercados digitais). 0 Grupo de Trabalho foi criado durante a 5a Conferência sobre Concorrência do BRICS em Brasília, em 2017, sob a coordenação do Cade.

Adotou-se, neste documento, uma ampla definição de Economia Digital, ou seja, negócios que fornecem produtos e/ou serviços que utilizam tecnologias de informação e comunicação, especialmente a Internet, com amplo uso de dados.

O Relatório teve por objetivo dar uma visão geral das inovações da política e práticas de defesa da concorrência nesses países em relação aos mercados digitais sob os seguintes aspectos: avaliação do poder de mercado, inovação e concorrência dinâmica, aquisição de empresas entrantes por incumbentes, barreiras à entrada, precificação algorítmica e big data.

Além disso, o documento apresenta uma lista de casos selecionados que exemplificam as experiências recentes das autoridades de defesa da concorrência que envolvem a economia digital.

Os casos de fusões/aquisições mais relevantes elencados pelo Cade referentes à economia digital foram: Banco Bradesco S/A., Banco do Brasil S/A., Banco Santander (Brasil) S/A., Caixa Econômica Federal e Itaú Unibanco S/A (criação de um bureau de crédito); Bayer/Monsanto; Itaú/XP Investimentos; Warner/AT\&T; Rocket/Naspers e Disney/Fox . Entre os casos elencados, verificou-se que o Cade analisou efeitos conglomerados nos seguintes atos de concentração: Bayer/Monsanto, Itaú/XP e Disney/Fox ${ }^{29}$.

De acordo com o citado Relatório, o Cade considera que, um dos principais desafios na aplicação da defesa da concorrência nos mercados digitais é determinar como intervir em mercados altamente dinâmicos. Em tais mercados, se por um lado, uma intervenção pode ser necessária para proteger a concorrência e os consumidores, por outro, pode-se prejudicar a inovação ou ter efeitos exclusionários não intencionais.

Especificamente no mercado de alta tecnologia, a formação de conglomerados está relacionada, a princípio, com a dinâmica de competição e inovação desses mercados, que ao utilizar plataformas de múltiplos lados potencializam efeitos de rede (externalidades de rede) e controle de dados, o que podem levar a abusos de poder dominante.

Nesse contexto, o Cade considera uma tarefa particularmente desafiadora estimar os efeitos a longo prazo da intervenção da política de concorrência e adaptar medidas adequadas às especificidades da economia digital, em particular nos mercados de alta tecnologia, nos quais a inovação é notavelmente mais dinâmica.

Por fim, quanto ao arcabouço jurídico, nenhuma alteração formal específica na legislação está sob análise para abordar especificamente a economia digital. O mesmo se aplica às mudanças nos limites de notificação, uma vez que o direito da concorrência brasileiro fornece ao Tribunal Ad-

29 ACs nos 08700.002792/2016-47 (Requerentes: Banco Bradesco S/A., Banco do Brasil S/A., Banco Santander (Brasil) S/A., Caixa Econômica Federal e Itaú Unibanco S/A); 08700.001097/2017-49 (Requerentes: Bayer Aktiengesellchaft e Monsanto Company); 08700.004431/2017-16 (Requerentes: Itaú Unibanco S/A e XP Investimentos S/A); 08700.001390/2017-14 (Requerentes: AT\&T Inc. e Time Warner Inc.); 08700.007262/2017-76 (Rocket Internet SE e Naspers Ventures B.V.); 08700.004494/2018-53 (Requerentes:Twenty-first Century Fox, Inc. e The Walt Disney Company (Brasil) Ltda.). 
ministrativo do Sistema Brasileiro de Defesa da Concorrência a possibilidade de analisar qualquer fusão e aquisição mediante solicitação, no prazo de um ano após a assinatura do contrato, independentemente das vendas brutas anuais das partes ou faturamento total.

\section{CONCLUSÃO}

Atualmente pode-se afirmar que, diante das análises de controle de concentrações do Cade em relação a efeitos conglomerados, notam-se avanços nos seguintes aspectos: (i) ampliação da análise, para além do chamado efeito portfólio, com a incorporação de outras teorias do dano; e (ii) a utilização crescente de análises econômicas por meio de estudos quantitativos e qualitativos.

No que tange às teorias do dano utilizadas na análise de efeitos conglomerados, apesar da preponderância da teoria da atuação transversal como contraposição ao aumento do poder de portfólio, nota-se que o Cade tem ampliado argumentos que vão ao encontro de outras teorias do dano como redução da concorrência (subtantial lessening of competition) e fortalecimento do poder econômico (Entrenchment Doctrine).

Essa ampliação do uso de diferentes teorias do dano tem levado a preocupações crescentes por parte dos Conselheiros do Cade com determinados setores econômicos, especialmente os setores bancário, agrícola e educacional, conforme os votos relativos a atos de concentração mencionados anteriormente (vide Seção 3.2).

Vale mencionar também o mercado de saúde, especificamente o de saúde suplementar que, embora não haja muitos casos de análises de efeitos conglomerados, há um caminho promissor para esse tipo de análise dadas as mudanças estruturais ocorridas neste segmento nos últimos anos, em especial um processo de ampliação de portfólio, conforme explicitado anteriormente.

Acrescente-se que um dos instrumentos que o Cade tem utilizado de forma crescente em atos de concentração é análise econômica que, a partir de estudos quantitativos e qualitativos, aborda questões relativas à eficiência, rivalidade no mercado, poder de barganha, entre outros. Alguns desses casos, como visto anteriormente, envolvem análises de efeitos conglomerados, cujos estudos tem contribuído para embasar decisões do Tribunal do Cade.

Por fim, apesar de não ter sido o foco do presente artigo, vale mencionar que o Cade tem agido mais em condutas anticompetitivas do que propriamente em controle de estruturas, quando se trata do mercado de alta tecnologia. Essas empresas, em geral, operam como multiplataformas e possuem, entre outras características, fortes efeitos de rede (externalidades de rede) com baixo custo unitário, domínio dos dados dos agentes econômicos e uma dinâmica específica de precificação fixada no preço monetário zero de um lado do mercado, o que desafia uma análise econômica convencional com base nos preços.

A título de exemplo, vale mencionar os processos investigativos instaurados pela Autarquia cujas representadas foram Google Inc. e Google Brasil Internet Ltda., denunciadas por abuso de po- 
sição dominante ${ }^{30}$.

Nesse contexto, não se pode descartar a possibilidade de que esses casos de condutas unilaterais na economia digital sejam um importante indicativo para questionamentos futuros quanto à eficácia de instrumentos de uma análise antitruste tradicional de atos de concentração que se baseia, preponderantemente, em sobreposições horizontais e integrações verticais.

Por consequência, análises de efeitos conglomerados tornam-se cada vez mais relevantes, não apenas devido ao ressurgimento de players gigantes, com potencial crescente poder de mercado e atuação transversal em vários setores da economia, como, também, devido a aquisições de empresas mavericks, por incumbentes, que comprometem, em determinados casos, a contestabilidade do mercado. Com isso, a aplicação de novas teorias do dano e realização de estudos econômicos tem sido um caminho promissor para a atuação do Cade.

\section{REFERENCIAS}

BINOTTO, Anna. Efeitos conglomerados em concentrações econômicas: caracterização e desdobramento. In: JESUS, Agnes M. et al. (org.). Mulheres no antitruste. São Paulo: Editora Singular, 2018. Disponivel em: http://www.direitorp.usp.br/wp-content/uploads/2018/10/Mulheres-no-Antitruste-Volume-I-V.-Final.pdf Acesso em: 12 abr 2020.

BouRREAU, Marc; de STREEL, Alexandre. Digital Conglomerates and EU Competition Policy. Université de Namur, Telecom ParisTech, março 2019. Disponivel em: http://www.crid.be/pdf/public/8377.pdf Acesso em: 24 nov 2020.

BRASIL. Lei no 12.529, de 30 de novembro de 2011. Estrutura o Sistema Brasileiro de Defesa da Concorrência. Disponivel em: http://www.planalto.gov.br/ccivil_03/_ato2011-2014/2011/lei//12529.htm Acesso em: 24 nov 2020.

BRASIL. Conselho Administrativo de Defesa Econômica. Ato de Concentração no 08700.001097/201749 (Requerentes: Bayer Aktiengesselschaft e Monsanto Company). Disponivel em: http://www.cade. gov.br/assuntos/processos-1 Acesso em: 12 abr 2020.

BRASIL. Conselho Administrativo de Defesa Econômica. Ato de Concentração no 08700. 005447/201312 (Requerentes: Kroton Educacional S/A e Anhanguera Educacional Participações S/A). Disponível em: http://www.cade.gov.br/assuntos/processos-1 Acesso em: 12 abr 2020.

BRASIL. Conselho Administrativo de Defesa Econômica. Ato de Concentração no 08700.006345/201829 (Requerentes: Itaú Unibanco S/A e Ticket Serviços S/A). Disponível em: http:/ /www.cade.gov.br/ assuntos/processos-1 Acesso em: 12 abr 2020.

30 Recentemente o Cade analisou os seguintes casos de conduta: Processo Administrativo 08700.005694/2013-19 (Representante: Cade ex officio, Representadas: Google Inc. e Google Brasil Internet Ltda. - sobre alegada conduta unilateral/ abuso de posição dominante por cópia de conteúdo/scraping; Processo Administrativo 08700.009082/2013-03 (Representante: E-Commerce Media Group Informação e Tecnologia Ltda., Representadas: Google Inc. e Google Brasil Internet Ltda. - sobre alegada conduta unilateral/abuso de posição dominante por imposição de cláusulas abusivas que impedem o uso de plataformas rivais); e Processo Administrativo 08012.010483/2011-94 (Representante: E-Commerce Media Group Informação e Tecnologia Ltda, Representadas: Google Inc. e Google Brasil Internet Ltda. - sobre alegada conduta unilateral/abuso de posição dominante por favorecimento ao Google Shopping). 
BRASIL. Conselho Administrativo de Defesa Econômica. Ato de Concentração no 08700.004203/201916 (Requerentes: Danaher Corporation e General Electric Company). Disponivel em: http:/ /www.cade. gov.br/assuntos/processos-1 Acesso em: 12 abr 2020.

BRASIL. Conselho Administrativo de Defesa Econômica. Ato de Concentração no 08700.04162/201879 (Requerentes: Saint-Gobain do Brasil Produtos Industriais e para Construção Ltda. e Rockfibras do Brasil Indústria e Comércio Ltda.) Disponivel em: http://www.cade.gov.br/assuntos/processos-1 Acesso em: 12 abr 2020.

BRASIL. Conselho Administrativo de Defesa Econômica. Ato de Concentração no 08700.008483/201681 (Requerentes: WEG Equipamentos Elétricos S/A e TGM Indústria e Comércio de Turbinas e Transmissões Ltda.). Disponivel em: http://www.cade.gov.br/assuntos/processos-1 Acesso em: 12 abr 2020. BRASIL. Conselho Administrativo de Defesa Econômica. Ato de Concentração no 08700.009988/201409 (Requerentes: Tigre S/A - Tubos e Conexões e Condor Pincéis Ltda.). Disponível em: http://www. cade.gov.br/assuntos/processos-1 Acesso em: 12 abr 2020.

BRASIL. Conselho Administrativo de Defesa Econômica. Ato de Concentração 08700.004431/2017-16 (Requerentes: Itaú Unibanco S/A e XP Investimentos S/A). Disponivel em: http://www.cade.gov.br/ assuntos/processos-1 Acesso em: 12 abr 2020.

BRASIL. Conselho Administrativo de Defesa Econômica. Ato de Concentração no 08700.006185/201656 (Requerentes: Kroton Educacional S/A e Estácio Participações S/A) Disponível em: http://www. cade.gov.br/assuntos/processos-1 Acesso em: 12 abr 2020.

BUNDESKARTELLAMT. Conglomerate Mergers in Merger Control: Review and Prospects. Discussion paper, 21 set 2006. Disponivel em: https://www.bundeskartellamt.de/SharedDocs/Publikation/EN/ Fachartikel/Conglomerate\%20Mergers.pdf?__blob=publicationFile\&v=3 Acesso em: 24 nov 2020.

CHENG, Thomas K. Sherman vs. Goliath?: Tackling the Conglomerate Dominance Problem in Emerging and Small Economies - Hong Kong as a Case Study. Northwestern Journal of International Law \& Business, v. 37, n. 1, p. 35-105, 2017. Disponivel em: https://asean-competition.org/research/research/ sherman-vs-goliath-tackling-the-conglomerate-dominance-problem-in-emerging-and-small-economies-hong-kong-as-a-case-study Acesso em: 24 nov 2020.

GARCIA, C. P \& AZEVEDO, P. F. Should competition authorities care about conglomerate mergers? World Economics Association Conferences, 2017. Disponivel em: http://lawandeconomics2017.weaconferences.net/files/2017/05/WEA-LawAndEconomicsConference2017-PolicarpoFurquim.pdf Acesso em: 08 abr 2020.

GOLDBERG, L. The Effect of Conglomerate Mergers on Competition. The Journal of Law \& Economics, v. 16/1, p. 137-158, 1973. Disponivel em: https://www.jstor.org/stable/724829?seq=1 Acesso em: 24 nov 2020.

HEMPHILL, Scott C.; WU, Tim. Parallel Exclusion. The Yale Law Journal, v. 122, p. 1182-1253, 2012. Disponivel em: https://core.ac.uk/download/pdf/157779413.pdf Acesso em: 24 nov 2020.

HOVENKAMP, H. Federal Antitrust Policy: the law of competition and its practice. 4. Ed. St. Paul, Hornbook series, 2011.

KHAN, Lina M. Amazon's Atitrust Paradox, The Yale Law Journal, v. 126, n. 3, p. 710-805, 2017. Disponível 
em: https://digitalcommons.law.yale.edu/cgi/viewcontent.cgi?article=5785\&context=ylj Acesso em: 24 nov 2020.

LIM, Yong. Tech Wars: Return of the Conglomerate - Throwback or Dawn of a New Series for Competition in the Digital Era? Journal of Korean Law, v. 19, p. 47-62, 2017. Disponivel em: https:/ /papers.ssrn. com/sol3/papers.cfm?abstract_id=3051560 Acesso em: 10 set 2021.

NEVEN, D. The analysis of conglomerate effects in EU merger control. Graduate Institute of International Studies, Geneva and CEPR, 2005. Disponivel em: https://ec.europa.eu/dgs/competition/economist/conglomerate.pdf Acesso em: 12 abr 2020.

$\mathrm{OECD}$, Guidelines on the assessment of non-horizontal mergers under the Council Regulation on the control of concentrations between undertakings. 2008 Disponivel em: https:/ /eur-lex.europa.eu / legal-content/EN/TXT/?uri=CELEX\%3A52008XC1018\%2803\%29 Acesso em: 1o dez 2020.

OECD, Triple and Quadruple Play Bundles of Communication Services. 2015 Disponivel em: [https:/ / www.oecd-ilibrary.org/triple-and-quadruple-play-bundles-of-communication-services_5js04dp2q1jc.pdf Acesso em: 24 nov 2020.

OECD, Roundtable on Conglomerate Effects of Mergers. 2020 Disponivel em: https://one.oecd.org/ document/DAF/COMP(2020)2/en/pdf Acesso em: 24 nov 2020

TIROLE, Jean. Regulating the disrupters. ING Think, 4 jan 2019. Disponivel em: https://think.ing.com/ downloads/pdf/opinion/jean-tirole-regulating-the-disrupters Acesso em: 11 set 2020.

\section{ANEXOS}

Tabela 1 - Operações conglomerais a partir da Lei 12.529/2011

\begin{tabular}{|c|c|c|c|}
\hline Número & Requerentes & $\begin{array}{c}\text { Data de Julga- } \\
\text { mento }\end{array}$ & Decisão \\
\hline $08700.000741 / 2020-67$ & $\begin{array}{c}\text { Fras-Le S/A e Nakata Automotiva } \\
\text { S/A }\end{array}$ & $17 / 06 / 2020$ & Aprovação sem restrições \\
\hline
\end{tabular}

31 A seleção dos atos de concentração que compõe a presente tabela baseou-se em pesquisa de jurisprudência no Sistema SEI e pesquisa na doutrina econômica. Trata-se de uma lista não exaustiva, visto que não há uma definição padrão para efeitos conglomerados. Com relação à pesquisa no Sistema SEI, foram elencados os atos de concentração de acesso público nos quais foram identificadas análises do Cade que tratam de efeitos conglomerados (ou efeito/poder de portfólio) em votos de Conselheiros e/ou pareceres da SG, o que inclui os documentos anexos, ou seja, anexo ao voto e/ou anexo ao parecer SG. Para isso, foi utilizada a ferramenta "pesquisa" seguindo os seguintes passos: 1ㅇ) selecionou-se "texto para pesquisa" com as seguintes palavras-chave: "efeitos conglomerados" "efeito conglomerado", "conglomerais", "conglomeral", "efeito portfólio", "poder de portfólio", "reforço no portfólio" e "reforço de portfólio" (obs: cada palavra-chave foi selecionada por vez), 2o) selecionou-se "tipo de documento": "Voto", "Voto Ato de Concentração" "Parecer" e "Anexo", 3o) selecionou-se "Data do documento", "período explícito" por ano, ou seja, 1ㅇ/06/2012 a 31/12/2012 (início da vigência da Lei 12.529/2011), 1ㅇ/01/2013 a 31/12/2013, e assim por diante até 10/01/2020 a 31/12/2020. Vale mencionar que há casos em que foram encontrados ACs de acordo com os padrões da pesquisa descrita acima, mas que não foram incluídos na tabela visto que não há uma análise de efeito portfólio/conglomerado decorrente da operação, e.g., AC no 08700.004270/2020-66, AC ํo 08700.004888/2018-10, 08700.004830/2020-82, 08700.002327/2018-78 e 08700.001390/2017-14. Por fim, há ACs em que não há uma análise do Cade sobre efeitos conglomerados. No entanto foram incluídos na tabela devido ao respaldo da doutrina econômica. Especificamente, trata-se do artigo Should competition authorities care about conglomerate mergers?, de Carolina Policarpo Garcia e Paulo Furquim de Azevedo, que analisa fusões conglomeradas no setor de ensino superior no Brasil. Os atos de concentração incluídos, baseados neste texto, foram: 08700.005447/2013-12 e 08700.009198/2013-34. 


\begin{tabular}{|c|c|c|c|}
\hline 08700.001908/2019-73 & $\begin{array}{l}\text { International Business Machines } \\
\text { Corporation - IBM; Red Hat, Inc. }\end{array}$ & $21 / 11 / 2019$ & Aprovação sem restrições \\
\hline 08700.002074/2019-13 & $\begin{array}{c}\text { Ambev S/A e Red Bull do Brasil } \\
\text { Ltda. }\end{array}$ & $17 / 09 / 2019$ & Aprovação sem restrições \\
\hline 08700.002403/2019-26 & $\begin{array}{c}\text { Cameron International Corpo- } \\
\text { ration (Grupo Schlumberger) } \\
\text { e Subsea } 7 \text { Holdings (US) Inc. } \\
\text { (Grupo Subsea 7) }\end{array}$ & $28 / 05 / 2019$ & Aprovação sem restrições \\
\hline 08700.002780/2019-65 & $\begin{array}{l}\text { QIAGEN GMBH e General Eletric } \\
\text { Company (GE) }\end{array}$ & $19 / 07 / 2019$ & Aprovação sem restrições \\
\hline 08700.003245/2019-21 & $\begin{array}{c}\text { Rede D’Or São Luiz S/A e Casa } \\
\text { de Saúde Laranjeiras Ltda., } \\
\text { Unidade Neonatal da Lagoa } \\
\text { Ltda. e Cia de Serviços Especiais } \\
\text { e Unificados Ltda. }\end{array}$ & $17 / 12 / 2019$ & Aprovação sem restrições \\
\hline 08700.004203/2019-16 & $\begin{array}{c}\text { Danaher Corporation e General } \\
\text { Electric Company }\end{array}$ & $04 / 11 / 2019$ & Aprovação sem restrições \\
\hline 08700.001324/2018-17 & $\begin{array}{l}\text { United Technologies Corpora- } \\
\text { tion e Rockwell Collins, Inc. }\end{array}$ & $10 / 05 / 2018$ & Aprovação sem restrições \\
\hline 08700.004162/2018-79 & $\begin{array}{l}\text { Saint-Gobain do Brasil Produtos } \\
\text { Industriais e para Construção } \\
\text { Ltda. e Rockfibras do Brasil In- } \\
\text { dústria e Comércio Ltda. }\end{array}$ & $14 / 05 / 2019$ & Arquivamento: perda de objeto \\
\hline 08700.004494/2018-53 & $\begin{array}{c}\text { The Walt Disney Company (Bra- } \\
\text { sil) Ltda. e Twenty-First Century } \\
\text { Fox, Inc. }\end{array}$ & 28/02/2019 & Aprovação com restrições \\
\hline 08700.004901/2018-22 & Fras-Le S/A e Jofund S/A & $17 / 09 / 2018$ & Aprovação sem restrições \\
\hline 08700.006345/2018-29 & $\begin{array}{c}\text { Itaú Unibanco S/A e Ticket Ser- } \\
\text { viços S/A }\end{array}$ & 02/07/2019 & Aprovação sem restrições \\
\hline 08700.001097/2017-49 & $\begin{array}{c}\text { Bayer Aktiengesellschaft (Bayer) } \\
\text { e Monsanto Company (Mon- } \\
\text { santo) }\end{array}$ & $16 / 02 / 2018$ & Aprovação com restrições \\
\hline 08700.003430/2017-54 & $\begin{array}{l}\text { Deere \& Company (Deere) e } \\
\text { Wirtgen Group Holding GmbH } \\
\text { (Wirtgen Holding) }\end{array}$ & $03 / 08 / 2017$ & Aprovação sem restrições \\
\hline 08700.004431/2017-16 & $\begin{array}{c}\text { Itaú Unibanco S/A e XP Investi- } \\
\text { mentos S/A }\end{array}$ & $20 / 03 / 2018$ & Aprovação com restrições \\
\hline 08700.004446/2017-84 & $\begin{array}{c}\text { Essilor International (Compagnie } \\
\text { Générale d'Optique) S/A (Essi- } \\
\text { lor) e } \\
\text { Luxottica Group S.p.A. (Luxot- } \\
\text { tica) }\end{array}$ & $23 / 02 / 2018$ & Aprovação sem restrições \\
\hline 08700.005534/2017-01 & $\begin{array}{l}\text { Saint-Gobain do Brasil Produtos } \\
\text { Industriais e para Construção } \\
\text { Ltda. (Saint-Gobain) e ATB In- } \\
\text { dústria e Comércio de Adesivos } \\
\text { S/A (ATB) }\end{array}$ & $27 / 11 / 2017$ & Aprovação sem restrições \\
\hline
\end{tabular}




\begin{tabular}{|c|c|c|c|}
\hline 08700.006606/2017-20 & $\begin{array}{c}\text { Safran S/A e Zodiac Aerospace } \\
\text { S/A }\end{array}$ & $27 / 12 / 2017$ & Aprovação sem restrições \\
\hline 08700.001221/2016-95 & $\begin{array}{l}\text { Coty Inc. (Coty) e Procter and } \\
\text { Gamble Company (P\&G) }\end{array}$ & 08/06/2016 & Aprovação sem restrições \\
\hline 08700.003462/2016-79 & $\begin{array}{c}\text { Reckitt Benckiser (Brasil) Ltda. e } \\
\text { Hypermarcas S/A }\end{array}$ & $20 / 09 / 2016$ & Aprovação com restrições \\
\hline 08700.004860/2016-11 & $\begin{array}{c}\text { BM\&FBovespa S/A - Bolsa de } \\
\text { Valores, Mercados e Futuros } \\
\text { (BVMF), Cetip } \\
\text { S/A - Mercados Organizados } \\
\text { (Cetip) }\end{array}$ & $28 / 03 / 2017$ & Aprovação com restrições \\
\hline 08700.005937/2016-61 & $\begin{array}{c}\text { The Dow Chemical Company e } \\
\text { E.I. Du Pont de Nemours and } \\
\text { Company }\end{array}$ & $23 / 05 / 2017$ & Aprovação com restrições \\
\hline 08700.006015/2016-71 & $\begin{array}{c}\text { Coca-Cola Indústrias Ltda. (CCIL), } \\
\text { Spal Indústria Brasileira de Be- } \\
\text { bidas S/A (Spal) e Unilever PLC } \\
\text { (Unilever) }\end{array}$ & $27 / 09 / 2016$ & Aprovação sem restrições \\
\hline 08700.006185/2016-56 & $\begin{array}{c}\text { Kroton Educacional S/A e Estácio } \\
\text { Participações S/A }\end{array}$ & $12 / 07 / 2017$ & Reprovação \\
\hline 08700.006269/2016-90 & $\begin{array}{l}\text { China National Agrochemical } \\
\text { Corporation e Syngenta Ag. }\end{array}$ & 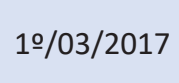 & Aprovação sem restrições \\
\hline 08700.008483/2016-81 & $\begin{array}{c}\text { WEG Equipamentos Elétricos } \\
\text { S/A (WEG) e TGM Indústria e } \\
\text { Comércio de Turbinas e Trans- } \\
\text { missões Ltda. (TGM) }\end{array}$ & 06/03/2018 & Aprovação com restrições \\
\hline 08700.001437/2015-70 & $\begin{array}{l}\text { Dabi Atlante S/A Indústrias } \\
\text { Médico Odontológica e Gnatus } \\
\text { Equipamentos Médico-Odonto- } \\
\text { lógicos Ltda. }\end{array}$ & $02 / 12 / 2015$ & Aprovação com restrições \\
\hline 08700.002721/2015-63 & $\begin{array}{l}\text { Duratex S/A (Duratex) e Ducha- } \\
\text { corona Ltda. (Corona) }\end{array}$ & $14 / 05 / 2015$ & Aprovação sem restrições \\
\hline 08700.006390/2015-31 & $\begin{array}{l}\text { Compagnie de Saint-Gobain } \\
\text { (Saint Gobain) e Schenker- } \\
\text {-Winkler Holding AG (SWH) }\end{array}$ & $17 / 11 / 2015$ & Aprovação sem restrições \\
\hline 08700.007191/2015-40 & $\begin{array}{c}\text { Halliburton Company e Baker } \\
\text { Hughes Incorporated }\end{array}$ & $31 / 05 / 2016$ & Arquivamento: perda de objeto \\
\hline 08700.009018/2015-86 & $\begin{array}{l}\text { Technicolor S/A (Technicolor) e } \\
\text { Cisco Systems, Inc. (Cisco) }\end{array}$ & $25 / 01 / 2016$ & Aprovação sem restrições \\
\hline 08700.003843/2014-96 & $\begin{array}{c}\text { Companhia Brasileira de Cartu- } \\
\text { chos (CBC) e Forjas Taurus S/A } \\
\text { (Taurus) }\end{array}$ & $26 / 01 / 2015$ & Aprovação sem restrições \\
\hline 08700.009988/2014-09 & $\begin{array}{l}\text { Tigre S/A - Tubos e Conexões } \\
\text { (Tigre) e Condor Pincéis Ltda. }\end{array}$ & 09/09/2015 & Reprovação \\
\hline 08700.005447/2013-12 & $\begin{array}{c}\text { Kroton Educacional S/A e } \\
\text { Anhanguera Educacional Partici- } \\
\text { pações S/A }\end{array}$ & $11 / 06 / 2014$ & Aprovação com restrições \\
\hline 08700.009198/2013-34 & $\begin{array}{c}\text { Estácio Participações S/A e TCA } \\
\text { Investimento em Participações } \\
\text { Ltda. (Grupo SEB) }\end{array}$ & $11 / 06 / 2014$ & Aprovação com restrições \\
\hline
\end{tabular}

Fonte: elaboração própria 